\title{
EARNING YOUR CAP: COMPREHENSIVE ANALYSIS OF THE UNIVERSITY OF TEXAS SYSTEM'S COORDINATED ADMISSIONS PROGRAM
}

\author{
Rodney J. Andrews \\ John Thompson \\ Working Paper 23442 \\ http://www.nber.org/papers/w23442 \\ NATIONAL BUREAU OF ECONOMIC RESEARCH \\ 1050 Massachusetts Avenue \\ Cambridge, MA 02138 \\ May 2017, Revised July 2017
}

The conclusions of this research do not necessarily reflect the opinions or official position of the Texas Education Agency, the Texas Higher Education Coordinating Board, the State of Texas, or the National Bureau of Economic Research.

NBER working papers are circulated for discussion and comment purposes. They have not been peerreviewed or been subject to the review by the NBER Board of Directors that accompanies official NBER publications.

(C) 2017 by Rodney J. Andrews and John Thompson. All rights reserved. Short sections of text, not to exceed two paragraphs, may be quoted without explicit permission provided that full credit, including (c) notice, is given to the source. 
Earning your CAP: A Comprehensive Analysis of The University of Texas System's Coordinated Admissions Program

Rodney J. Andrews and John Thompson

NBER Working Paper No. 23442

May 2017, Revised July 2017

JEL No. I21,I22,I26,J24

\begin{abstract}
The competitive application process is the traditional path to gain access to selective public universities. There is little research on alternative pathways to gain access to selective public universities. In this manuscript, we use the fuzzy regression discontinuity design to study the impact of transferring to the University of Texas at Austin. We find that gaining access via this path has an impact on choice of major, financial aid, and earnings.
\end{abstract}

Rodney J. Andrews

The University of Texas at Dallas

800 West Campbell Road

MS WT21

Richardson, TX 75080

and NBER

rodney.j.andrews@utdallas.edu

John Thompson

The University of Texas at Dallas

jct083000@utdallas.edu 


\section{Introduction}

The University of Texas at Austin has featured prominently in the national debate over which factors colleges- in particular, selective public colleges - can and should use to make admission decisions. The Top Ten Percent Rule, which grants automatic admission to Texas high school graduates who finish in the top decile of their graduating class, was made law by the Texas Legislature in 1997 to address the large declines in African American and Hispanic enrollments at Texas's selective public universities. Subsequently, both California and Florida adopted similar rank based admission policies. In the wake of the United States Supreme court's decision in Grutter $v$. Bollinger, which upheld the use of race in the college admissions process, The University of Texas at Austin resumed the use of race as a factor in admissions. The most recent legal challenge to the use of race in admissions, Fisher $v$. Texas, was levied against this use of race as a factor in undergraduate admissions. Gaining admission as a first-time entering freshman is the traditional path to an undergraduate education at selective public universities. The policies that determine access via this path have received a great deal of both publicity and legal scrutiny. Indeed, there is a vast literature in economics devoted to the study of the effect of changes in undergraduate admissions policies on a number of educational and labor market outcomes. ${ }^{1}$ However, given the salience of access to selective public universities, it is surprising that so little attention has been given to the study of alternative means of gaining access to these institutions. This paper addresses this deficit in our knowledge directly via a comprehensive, quasi-experimental evaluation of an alternative path to The University of Texas at Austin provided by the Coordinated Admissions Program. ${ }^{2}$

The Coordinated Admissions Program (CAP) was established by The University of Texas System's board of regents in November of 2000 in an effort to "avoid "Closing the Door"

\footnotetext{
${ }^{1}$ Arcidiacono and Lovenheim (2016) provides a detailed summary of this literature.

${ }^{2}$ Andrews, Li, and Lovenheim (2014) is an exception as it analyzes different transfer paths to Texas's Flagship institutions. However, the authors make clear that the paper is explicitly descriptive and do not ascribe a causal interpretation to their findings.
} 
on any Texas Resident.' (CAP Report 1, 2003) The CAP emerged as a response to the increase in both applications and admissions to The University of Texas at Austin due to Texas's Top Ten Percent Rule. (CAP Report 1, 2003) The CAP is essentially an articulation agreement between The University of Texas at Austin and participating University of Texas System campuses. Texas residents who both apply to The University of Texas at Austin and are then denied admission are offered the opportunity to enter into a contract with the University of Texas system. The contract states that if a student completes their freshman year at a participating institution and meets certain eligibility criteria, then the student is guaranteed the option to transfer to The University of Texas at Austin as a sophomore the following fall semester. The participating University of Texas System institutions include UT-Arlington, UT-Brownsville, UT-El Paso, UT-Pan American, UT-Permian Basin, UTSan Antonio, and UT-Tyler. ${ }^{3}$ Chief among the eligibility requirements, for our purposes, is that a student must obtain a minimum Grade Point Average (GPA) of 3.0 to qualify for the option to transfer. ${ }^{4}$ Similar to Andrews (2016), we use the regression discontinuity design to exploit this feature of the Coordinated Admissions Program to estimate the causal impact of taking this path to The University at Austin. However, our analysis differs substantially in the following ways. First, we demonstrate that the CAP represents a new pathway to the University of Texas System's flagship campus. Second, we analyze a larger time frame which includes more cohorts. Finally, we examine the impact of the CAP on a more comprehensive set of outcomes - which includes, for example, student financial aid and earnings - that better characterize the entirety of the collegiate experience with regards to students choices, academic performance, and subsequent labor market success.

There are large differences in measures of college quality, selectivity, and demographics between The University of Texas at Austin and the participating University of Texas System institutions. Table 1 uses data from the Integrated Postsecondary Education Data System

\footnotetext{
${ }^{3}$ UT-Arlington, UT-El Paso, UT-Pan American, and UT-Permian Basin, and UT-San Antonio were CAP participating institutions for the entirety of our sample, from 2001 until 2008. UT-Brownsville became a participating institution in 2003 while UT-Tyler became a participating institution in 2005.

${ }^{4}$ Beginning in 2005, the minimum GPA requirement was raised to a 3.2
} 
for the year 2001 to compare The University of Texas at Austin and the CAP participating institutions. The University of Texas at Austin pays its faculty members more. Male faculty members received an average salary of $\$ 100,269$ dollars relative to an average of $\$ 74,012$. for male faculty members at CAP participating institutions. Female faculty members at UT Austin received an average salary of $\$ 89,545$ relative to a salary of $\$ 70,302.80$. UT Austin's Expenditures per student, at $\$ 6,079.81$, are more than twice the average expenditure per student at CAP participating institutions, $\$ 2,516.71$. The six year graduation rate at The University of Texas at Austin, approximately 70 percent, is substantially higher than than the six year graduation rate at CAP participating institutions which is around 28 percent. Students at The University of Texas at Austin also have significantly higher SAT Scores; the seventy fifth percentile for both the math and verbal SAT scores at The University of Texas at Austin exceeds the comparable scores at CAP participating institutions by more than one hundred points. The differences between the University of Texas at Austin and the CAP participating institutions in SAT math and verbal scores at the twenty-fifth percentile are nearly as large. The student body at The University of Texas at Austin has a far higher percentage of both white and Asian students while the CAP participating institutions student bodies' are more than one-half Hispanic. As Table 1 makes clear, the transition to The University of Texas at Austin necessarily involves large differences in resources, academic rigor, and peers. A priori, it is theoretically ambiguous as to how the differences between The University of Texas at Austin and the CAP participating institutions impact student performance. This is a question that must be addressed empirically.

Our findings contribute to several distinct strands of research that examine the effects of college choice and college quality on a variety of outcomes. First, we contribute to the set of studies - such as, Bound, Lovenheim, and Turner (2010), Bound, Lovenheim, and Turner (2012), and Cohodes and Goodman (2014) - that investigate the effects of college quality on persistence and graduation. Second, we contribute to the literature that investigates the relationship between college quality and choice of major. Arcidiacano, Aucejo, and 
Hotz (2016), using data from California, find that students of lower ability are more likely finish with science majors when they attend lower quality colleges. Arcidiacono (2004) and Arcidiacono (2005) uncover evidence of ability sorting across major and colleges. That student ability both influences the quality of college that a student attends and the choice of major makes it difficult to isolate the impact of college on choice of major. In this paper, we compare students who just qualify for automatic transfer to The University of Texas at Austin to those who just fail to qualify for the option to transfer who, we argue, are indistinguishable with regards to ability and other important determinants of major choice. Therefore, we are able to identify the effects of college quality on college choice. Finally, we add to the literature - for example, Black, Smith, and Daniel (2005), Black and Smith (2006), Hoekstra (2009) and Andrews, Li, and Lovenheim (2016) - that examines the relationship college type/quality and the labor market by providing quasi-experimental estimates of the returns for students who take an alternative path to The University of Texas at Austin, The University of Texas system's flagship university, relative to continuing their education at participating University of Texas System schools.

To preview our results, we find that for students who are marginally admitted through the CAP there is little evidence of a change in 4-year, 5-year, or 6-year graduation rates, some evidence of decreases in final GPA, With regards to choice of final major, we see some evidence that CAP students are more likely to major in such fields as Economics, the Social Sciences, and Communications, and less likely to major in fields such as Business, Math, and Sciences. We find evidence which suggests that CAP students face a higher Cost of Attendance and receive more funds from both Grants and Scholarships, but find little evidence to suggest that there are differences in Federal Direct Loan amounts between CAP and non-CAP students. We also find some evidence of higher earnings for CAP transfer students.

The remainder of the paper is structured as follows. The Second section describes in detail the origin and structure of the Coordinated Admissions Program. We discuss the 
data used in the analysis and the methodology in the third and fourth sections, respectively. We present the results in section five. Section six concludes.

\section{Background}

Prior the CAP, The University of Texas at Austin used a Provisional Admissions Program. The Provisional Admissions Program began in 1962 as a conditional admissions alternative for Texas resident applicants who were unsuccessful in the fall admissions process. (CAP Report 1, 2003) The Provisional Admissions Program permitted any Texas resident to enter any University of Texas System institution, regardless of their high school record or score on the Scholastic Aptitude Test (SAT) or American College Test (ACT), provided that they graduated from an accredited high school with the required units and subjects as prescribed by the institution. (The University of Texas System Board of Regents, 2004) Provisional Admits were required to complete twelve hours of basic college course work during the summer and earn at least a 2.25 grade point average. If these goals were met, then these students were eligible to enroll for the subsequent fall semester as regularly admitted freshman students at The University of Texas at Austin. (CAP Report 1, 2003) Provisional Admissions, therefore, was a means of offering admission to The University of Texas at Austin to academically weaker students.

Texas House Bill 588 or the "Top Ten Percent" rule was signed into law on May 20, 1997 by then governor George W. Bush. The Top Ten Percent Rule grants automatic admission to any public college or university in Texas for any Texas Resident who graduates in the top decile of their high school, provided that they submit a completed application to an institution within two years of graduating. ${ }^{5}$ Following the passage of the Top Ten Percent

\footnotetext{
${ }^{5}$ Senate Bill 175, passed in the 81st Texas Legislative session, now permits The University of Texas at Austin (UT-Austin) to admit its estimate of the number of Top 10 Percent Rule students who will comprise 75 percent of its resident entering class. These students are to be admitted in order by rank, starting with the highest. Any remaining Top 10 Percent Rule applicants not admitted in the initial 75 percent become part of the general admission pool. The University of Texas at Austin estimated that the top 9 percent would be eligible for automatic admission. As a result of Texas House Bill 1843, 83rd Texas Legislative session, The
} 
Rule, competition for slots increased precipitously at The University of Texas at Austin. Enrollment Pressure peaked with the 2000 Summer/Fall Applicant Pool. The applicant pool increased from 18,930 in 1999 to 21,359 in 2000, a 13.7 percent increase, and the number of admits increased from 11,949 to 13,256, 10.9 percent increase. (CAP Report 1, 2003) Concurrently, Provisional Admission offers increased to more than 4,000. Of those 4,000, approximately 1,500 actually enrolled with 905 continuing into the fall. (CAP Report 1, 2003) Historically, one half of Provisional admits had continued on to the fall semester.

The increased competition for admission to The University of Texas at Austin changed the nature of the Provisional Admission Program. Prior to the passage of the Top Ten Percent Rule, the Provisional Admissions Program was a means of offering students who failed to gain admission during the fall semester - who were, presumably, on average, weaker students - an opportunity to matriculate to The University of Texas at Austin. The increased competition brought about by the passage of HB 588 had transformed the Provisional Admissions Program into alternative means of gaining admission to The University of Texas at Austin for applicants who saw their probability of admission decline precipitously given the Top Ten Percent Rule.

In November of 2000, the University of Texas System Board of Regents approved a revision to the Provisional Admission policy for The University of Texas at Austin. The revision created an off-site Provisional Admission Program. In addition, a moratorium was placed on both 2001 Spring freshman admissions and 2001 transfer admissions. Beginning with the Fall of 2001, Texas residents were offered either fall admission, summer freshman admission with no minimum grade point average requirements, or off-site Provisional Admission. (CAP Report 1, 2003) The last program, which was then called "Off-Site Provisional Admission", was eventually designated as the Coordinated Admissions Program (CAP).

The Coordinated Admissions Program works as follows: Suppose that a Texas resident applies for admission for either the fall or summer. If the student is denied admission to University of Texas at Austin may use this provision through the fiscal year 2018. (Texas Higher Education Coordinating Board, 2013) 
The University of Texas at Austin, then the University of Texas System uses the student's application information - for example, grades, class rank, SAT scores, and ACT scores - to determine which of the participating University of Texas System schools a student is eligible to attend. A student is not required to send a separate application to a participating UTSystem school. Once this decision has been made by University of Texas System, the student is offered a contract that states that if the student enrolls at a participating University of Texas System school, completes a minimum of 30 credit hours, and earns at least a 3.0 grade point average during the fall and spring semesters following high school graduation, then that student is offered the opportunity to automatically transfer to The University of Texas at Austin during the following fall and granted unconditional acceptance into The University of Texas at Austin's College of Liberal Arts and Sciences.

The Coordinated Admissions Program represents a new path to The University of Texas at Austin. Figure 1 shows transfer patterns over time for a number of cohorts at participating University of Texas System Institutions. Note that there is no evidence of students transferring at high rates prior to the implementation of the CAP. After the year 2000, we see a large increase in the number of students at CAP participating institutions who transfer to The University of Texas at Austin after the second semester which aligns with the beginning of the Coordinated Admissions Program. Transfers at other points during students' academic careers do not change appreciably over time. Table 2 provides counts of students who transfer during the fall semester of the sophomore year, the spring semester of the sophomore year, and the fall semester of the junior year. The number of students that transfer in the fall semester of their sophomore year in 2001 was more than eight times as large as the number of students who transferred from a CAP participating institution to The University of Texas at Austin in 2000. The number of students who transferred in the fall of the sophomore year peaked in 2003. Both the number of sophomores who transferred to The University of Texas at Austin in the spring semester and the number of juniors who transferred to The University of Texas at Austin in the fall semester remained fairly con- 
stant over time. In sum, the graph and Table 2 demonstrate that Coordinated Admissions Program introduced a new path to The University of Texas at Austin and did not merely codify a prior de facto path to The University of Texas at Austin.

\section{Data}

This study uses administrative data from the Texas Education Agency, the Texas Higher Education Coordinating Board (THECB), and the Texas Workforce Commission that is housed at The University of Texas at Dallas's Education Research Center to construct a panel of 8 high school graduating cohorts of potential CAP students. In order to conform with the requirements of CAP and garner sufficient coverage of background covariates, our sample consists of Texas residents who graduated from public high schools between 2001 and 2008, who received valid score codes during the first administration of their high school exit level examinations ${ }^{6}$ who were denied Fall admission to The University of Texas at Austin, enrolled at one of the CAP participating institutions, completed a total of at least 24 credit hours at the participating institution across the Fall and Spring semesters, and who have a cumulative GPA within one half of a grade point of the requisite GPA threshold.

To construct our sample, we assemble cohorts of high school seniors who graduate between Spring 2001 to and Spring 2008 using the Texas Public Education Information Management System (PEIMS). We merge on application data from from the THECB for students who applied to The University of Texas at Austin, and keep those students who were rejected. Next, we merge on college freshman enrollment, keeping those students who were rejected by UT Austin and who are enrolled for at least 24 hours at participating system schools, and merge on high school exit exam scores. This allows us to construct our full set of background covariates (including race/ethnicity, gender, Free or Reduced Price Lunch Eligibility, Limited English Proficiency Status, At Risk of dropping out status, and Gifted and Talented

\footnotetext{
${ }^{6}$ Texas high school exit exams are administered during the spring semester of either the students' Sophomore or Junior year.
} 
status). ${ }^{7}$ For the students in our sample, we track the following 5 years worth of college enrollment by semester(monitoring the school where they are enrolled, their declared major, the number of credit hours they attempt, and the number of credit hours they earn), merge on college graduation files (through 6 years), and merge on financial aid information (observations appear at a student school year level). Next, we collect quarterly earnings using administrative data from the Texas Workforce Commission (TWC), and generate a measure of logged average quarterly earnings. Since our sample runs through the 2008 high school graduating cohort, we are unable to generate an earnings measure which we feel is representative of lifetime earnings potential for all of the cohorts in our sample; because of this, we take the earnings for our early cohorts, and use this to generate a predicted measure for our entire sample. Specifically, we take all quarterly earnings observations, collected from each individual's unemployment insurance records. Next, we run a regression of the logged quarterly earnings on dummies for year and quarter. We keep the residuals from this regression, and average them for each individual and year to produce our earnings measure. Next, we keep the earnings corresponding to the 10th year after high school graduation for our first 3 cohorts, and on this sample we run a regression of our earnings measure on school major fixed effects ${ }^{8}$, extract our fixed effect coefficients, and merge these onto our data to construct our analysis sample's earning measure.

Our estimating sample consists of 3753 students. Demographically, 51 percent of our sample is White, 5 percent of our sample is African American, 20 percent of our sample is Asian, and 22 percent of our sample is Hispanic. 53 percent of our sample is Male, 21 percent of our sample were classified as Gifted and Talented, 10 percent were classified as being at risk of dropping out of high school, and 10 percent were classified as Economically

\footnotetext{
${ }^{7}$ Our background covariates are extracted from student's Senior high school enrollment files.

${ }^{8}$ Here, our measure of predicted earnings comes from the school and major coefficients of a wage regression of the form $Y_{i}=\gamma_{1} P_{i}+\gamma_{2} X_{i}+\epsilon_{i}$ where $Y_{i}$ is the average quarterly earnings 10 years post high school graduation, $P_{i}$ is the terminal major school combination for student $i$ at 6 years post high school graduation, $X_{i}$ is a matrix of individual $i$ 's covariates, including demographic controls and controls for ability, and $\epsilon_{i}$ is an error term. This regression is run for our 2001, 2002, and 2003 cohorts, and our coefficients for $\beta_{1}$ are then applied to students from all cohorts based on their terminal major/school combination
} 
Disadvantaged $^{9}$. On average, our sample scores 0.74 standard deviations above the mean standardized high school exit level math examinations (standardized by subject and year), and 0.59 standard deviations above the mean standardized high school exit level reading examinations (standardized by subject and year). ${ }^{10}$

\section{Methodology}

We use a fuzzy regression discontinuity research design to estimate the causal impact of taking the transfer path to The University of Texas at Austin offered by the Coordinated Admissions Program. In this section, we describe how the structure of the Coordinated Admissions Program permits us to characterize the effect of transfer to The University of Texas at Austin via estimation of both a Local Average Treatment Effect and Intent to Treat parameters.

\section{1}

The crux of our analysis centers on the following idea: Students who just qualify for automatic transfer to The University of Texas at Austin are exchangeable with students who just fail to qualify for the option to transfer. We take advantage of the fact that CAP requires students to attain a minimum average GPA of either a 3.0 or 3.2 (depending on the year of application) for the fall and spring semesters of their freshman year at one of the participating University of Texas System institutions to qualify for the option to transfer to The University of Texas at Austin. The running variable is the difference between the student's cumulative grade point average for the fall and spring semesters and the appropriate min-

\footnotetext{
${ }^{9}$ Here, Economic Disadvantaged status is predicated on a student's eligibility to receive Free or Reduced Price Lunch during their Senior year of high school.

${ }^{10}$ Exit level examinations are administered during the Spring semester of 10th grade during the TAAS administration (through 2003 in our sample period), and are administered in the 11th grade during the TAKS administration (from 2004 through the end of our sample period). From the first administration of exit level examinations, we standardize raw scores (by subject and year) to generate the scaled scores we use in our analysis.
} 
imum grade point average. Students for whom this difference exceeds zero qualify for the option to transfer. Provided that some additional assumptions hold, we can use the fuzzy regression discontinuity design to produce causal estimates.

We use earning a GPA above the threshold as an instrumental variable for attending The University of Texas at Austin. Formally, we use a two stage least squares (2SLS) setup to estimate the fuzzy regression discontinuity design. We estimate equations of the following form:

$$
Y_{i}=\beta_{1} D_{i}+\beta_{2} X_{i}+g\left(R_{i}\right)+\epsilon_{i}
$$

and

$$
D_{i}=\alpha_{1} \text { Above }_{i}+\alpha_{2} X_{i}+g\left(R_{i}\right)+\omega_{i}
$$

In (2), our First-Stage equation, $D_{i}$, the endogenous variable, represents the student's transfer status to The University of Texas at Austin and assumes a value of one if a student transfers and zero otherwise, Above ${ }_{i}$ is an indicator for having a GPA above the CAP threshold, $R_{i}$ is the running variable described above, $g\left(R_{i}\right)$ represents a flexible function of the running variable (specifically, we consider a linear specification, which we allow to vary differently above and below the GPA threshold), $X_{i}$ represents student background characteristics, and both $\epsilon_{i}$ and $\omega_{i}$ are error terms. Our coefficient of interest in the FirstStage, $\alpha_{1}$ depicted in Table 4, and represented graphically in Figure 2) represents the change in the likelihood of transferring The University of Texas at Austin which occurs when an individual crosses the GPA threshold. In order for $\mathrm{Above}_{i}$ to be a valid instrument for $D_{i}$, we need Above $i$ and $\omega_{i}$ to be orthogonal and $\mathrm{Above}_{i}$ and $D_{i}$ to be correlated. Contingent on these conditions holding, we can interpret $\beta_{1}$ from our two-stage least squares estimation as the Local Average Treatment Effect (LATE) associated with CAP, as in Imbens and Angrist (1994). 


\section{2}

Following the framework described in Lee and Lemieux (2010), to ascribe a causal interpretation to the estimate from the fuzzy regression discontinuity design, we require the following assumptions to hold: 1). Strong First-Stage; 2). Monotonicity; 3). Local Randomization; 4). Excludability. Given these assumptions, we are able to estimate the Local Average Treatment Effect of transferring to The University of Texas at Austin for the subset of students who transfer as a result of attaining a GPA score just above the requisite threshold.

\subsubsection{First Stage}

We require there to be a strong first-stage in order for our usage of a 2SLS estimation strategy to be applicable. We find that at a bandwidth of 0.10 grade points, a student who scores a GPA above the CAP threshold will experience an increase in the probability of attending The University of Texas at Austin of 24, that at a bandwidth of 0.25 grade points, a student who scores a GPA above the CAP threshold will experience an increase in the probability of attending The University of Texas at Austin of 29 percentage points, and that at a bandwidth of 0.50 grade points, a student who scores a GPA above the CAP threshold will experience an increase in the probability of attending The University of Texas at Austin of 40 percentage points. Both of our estimates are significant at a p-value of .01. See Table 4 and Figure 2 for evidence of this.

\subsubsection{Monotonicity}

We require that the way in which finishing above the CAP threshold influences the decision to transfer to The University of Texas at Austin operates in only one direction. We assume that students who attain a cumulative GPA above the minimum requirement, $\mathrm{Above}_{i}$ equal to one, are more likely to transfer to The University of Texas at Austin, and that there are no students will become less likely to transfer by earning a cumulative grade point average above the minimum threshold. This assumption rules out the existence of "defiers". In this 
setting, this assumptions seems reasonable.

\subsubsection{Local Randomization}

Lee (2008) formally demonstrates that the running variable being imperfectly manipulable leads to local randomization and shows that it is local randomization that makes individuals just and just below the threshold exchangeable. The regression discontinuity design allows us to present both statistical and graphical evidence to support the existence of local randomization.

If local randomization occurs, then the distributions of observable and unobservable characteristics for students just above and just below are statistically indistinguishable. Figures 3 through 13 show means of the pre-treatment variables for values of the running variable and overlay the scatter plots with lines fit to those means and corresponding 95 percent confidence intervals. In sum, the graphs demonstrate that our pre-treatment covariates trend smoothly through the threshold.

We follow the recommendation given in Lee and Lemieux (2010) and estimate a System of Seemingly Unrelated Regressions to determine if observable pre-treatment covariates are balanced. We estimate the following system of equations:

$$
\begin{aligned}
x_{1} & =\gamma_{1} \text { Above }_{i}+g\left(R_{i}\right)+\eta_{1} \\
\vdots & \vdots \\
x_{J} & =\gamma_{J} \text { Above }_{i}+g\left(R_{i}\right)+\eta_{J}
\end{aligned}
$$

where $x_{i}$ is a $n$ by 1 column vector that contains the values of $i^{t h}$ variable from $X_{i}$. The

results are contained in Table 5 . For a bandwidth of 0.10 , we find an increased likelihood of being at risk of dropping out of high school at the threshold. For a bandwidth of 0.25 , we find a decrease in the likelihood of a student being African American at the threshold. While 
for a bandwidth of 0.50 , we find an increase in the the likelihood of a student being Asian at the threshold. However, given the number of covariates that we test, it is unsurprising that some of the estimates achieve statistical significance. We also test the null hypothesis that all the $\hat{\gamma}_{i}$ are simultaneously equal to zero. For all of our bandwidths, we fail to reject the null hypothesis. Taken together, the graphical and statistical evidence with regards to the observable pre-treatment covariates support the local randomization assumption.

If the running variable is sufficiently manipulable, then the assumption of local randomization does not hold. McCrary (2008) proposes that a discontinuous change in the density of the running variable at the threshold is evidence of manipulation as it is consistent with students strategically engaging in behavior to exceed the minimum threshold. However, Barreca, Lindo, and Waddell (2016) point out that this diagnostic performs poorly when there is "heaping". Figure 14 shows the distribution of grade point average before and after the implementation of the coordinated admissions program. We see clear evidence of heaps at common values - for example, 2.0, 2.5, 3.0, etc-which is to be expected given the discrete nature of grades. Figure 15 shows the distribution of grade point within a 0.50 bandwidth of 3.0. There is a clear spike at 3.0 which we also saw in Figure 14. However, there is no appreciable change in distribution of the grade point average near the threshold after the implementation of the Coordinated Admissions Program. Given the increased importance of a 3.0 GPA after the CAP, if there were manipulation, then we would expect to see it manifest as a change in the density of the grade point average near the threshold after the passage of the CAP relative to what we observe prior to the CAP. The similarity of the grade distributions over time is consistent with the idea that implementation of the CAP isn't associated with strategic manipulation of the running variable.

\subsubsection{Excludability}

Excludability, in this context, means that we assume that earning a Freshman grade point average that exceeds the minimum requirement impacts the outcome solely through its in- 
fluence on the likelihood of transferring to The University of Texas at Austin. We run regressions in the form of Equation (2) with our outcome being transferring to either Texas A\&M University, Texas Tech University, or The University of Houston, with our results presented in Table 6. The accompanying graphs are in Figures 16 through 18. The results indicate that there is no evidence of a change in the probability of transferring to either Texas A\&M University or Texas Tech University and a statistically significant decrease in the probability of transferring to The University of Houston. Although the decrease in the likelihood of transferring to the University of Houston is statistically significant, it is substantively quite small (somewhere between .26 and .71 standard deviations below the mean value) and of the wrong sign to indicate the existence of a transfer program to The University of Houston. Therefore, we do not believe that it represents evidence of the violation of the excludability assumption.

However, as Jones (2015) demonstrates, violations of the exclusion restriction bias estimates of Local Average Treatment Effects. For example, if students who just fail to qualify for automatic transfer exert more effort as a result of assignment, then exclusion is violated, and we are unable to produce unbiased estimates of the Local Average Treatment Effect. For the sake of completeness, we also include Intent to Treat (ITT) estimates for each of our outcomes, which do not restrict the impact of assignment to treatment - whether or not a student scores above the threshold - to have an impact solely through transferring to The University of Texas at Austin. We estimate models of the following form:

$$
Y_{i}=\pi_{1} \text { Above }_{i}+\pi_{2} X_{i}+g\left(R_{i}\right)+\varepsilon_{i}
$$

The Intent to Treat parameter, $\pi_{1}$, measures the effect of the availability of the option to transfer and elides consideration of whether or not a student actually transfers. Given the other assumptions, we can produce an unbiased estimate of the Intent to Treat parameter regardless of whether or not the exclusion restriction holds. 


\section{Results}

We first examine outcomes for CAP students with regards to terminal outcomes. We then present estimates of the impact of the CAP on final college major (either graduating major, or terminal major if graduation is not attained). Lastly we discuss financial aid outcomes. Tables 7, 8 , and 9 display our results for bandwidths of 0.1 grade points (columns $3 \& 4$ ), 0.25 grade points (columns $5 \& 7$ ), and 0.500 grade points (columns $9 \& 10) .{ }^{11}$ We also include the mean value of each outcome for individuals who are a part of our control group in the respective bandwidths (columns $2,5, \& 8$ ).

ITT results, which estimate the impact of meeting the CAP qualifications, are presented in the third, sixth, and ninth columns. The LATE estimates, which estimate the effect of transferring to The University of Texas at Austin for students who are induced to transfer by meeting the CAP requirements, are presented in the fourth, seventh, and tenth columns.

\subsection{Terminal}

Table 7 displays the terminal outcome estimates for predicted earnings, graduation rates, and final cumulative GPA. Our ITT estimates suggest that qualifying to transfer to The University of Texas at Austin through the CAP is associated with a 2 to 6 percentage point increase in the probability of bachelor degree completion (within 4, 5, or 6 years) for the bandwidths of 0.25 and 0.50 , and a -3 to 5 percentage point increase in degree completion for a bandwidth of 0.10. Our LATE estimates suggest that for those students who are induced to transfer through the CAP, there is an increase in the likelihood of graduating of between 8 and 20 percentage points for our bandwidths of 0.25 and 0.50 , and between a -15 and 21 percentage point increase in degree completion for a bandwidth of 0.10. Our results for a bandwidth of 0.10 appear to be imprecisely measured zeros. Estimates at the larger bandwidths appear to gain precision and are consistent in terms of their magnitude. Although these results are not statistically significant they appear to be

\footnotetext{
${ }^{11}$ Complete results for all bandwidths between 0.10 and 0.50 at intervals of 0.05 are available upon request
} 
economically substantive. The LATE estimates from the 0.50 range from 5 to 31 percent of the control group mean value. These results suggest that CAP transfers are no less likely to graduate within 4,5 , or 6 years and, furthermore, we find some evidence which suggests that CAP students are more likely to graduate within these time frames.

Looking at predicted earnings, calculated as described in section $3,{ }^{12}$ our ITT estimates suggest that the offer of transferring through CAP is associated with between 3 and 16 percentage point increase in predicted earnings. The LATE estimates suggest that CAP transfers have predicted earnings between 7 and 70 percentage points higher than their non-CAP peers. These results are statistically significant at the narrowest bandwidths, but are not at larger bandwidths. Results are consistently large across all bandwidths. Our estimated LATE coefficients for earnings range between .14 and 1.76 standard deviations above the mean value of predicted earnings, suggesting that these results are economically significant even when they may not be statistically significant.

Regarding Cumulative Final GPA, our ITT estimates suggest that the offer to transfer through the CAP is associated with a decrease in final GPA of between .4 and .11 grade points. Our LATE estimates suggest that CAP transfers are associated with a decrease in final GPA of between .13 and .29 grade points. Our results are statistically significant at a bandwidth of 0.50 , and are consistently large across all bandwidths. The LATE estimates correspond to between .19 and .42 standard deviations below the mean value, suggesting a non-negligible decrease in grades associated with the CAP.

Taken together, these results suggest that although there are negative impacts of the CAP with regards to Final GPA, these seem to have no negative effects, and some potentially small positive impacts of the CAP on graduating with a bachelor's degree within 4, 5, or 6 years, and that there is evidence of increased earnings for CAP transfer students.

\footnotetext{
${ }^{12}$ Here, our measure of predicted earnings comes from the school and major coefficients of a wage regression of the form $Y_{i}=\gamma_{1} P_{i}+\gamma_{2} X_{i}+\epsilon_{i}$ where $Y_{i}$ is the average quarterly earnings 10 years post high school graduation, $P_{i}$ is the terminal major school combination for student $i$ at 6 years post high school graduation, $X_{i}$ is a matrix of individual $i$ 's covariates, including demographic controls and controls for ability, and $\epsilon_{i}$ is an error term. This regression is run for our 2001, 2002, and 2003 cohorts, and our coefficients for $\beta_{1}$ are then applied to students from all cohorts based on their terminal major/school combination.
} 


\subsection{Major Outcomes}

Table 8 presents estimates of the impact of the CAP on final college major (either graduating major, or terminal major if graduation is not attained). We find that the offer to transfer through the CAP leads to a 3 to 4 percentage point increase in the likelihood of majoring in Economics. Our LATE estimates suggest that CAP transfers are associated with an increase in the likelihood of majoring in Economics of 8 to 18 percentage points. All of these results are statistically significant, and are consistently large across all of our bandwidths. Our LATE coefficients suggest an increase in the probability of majoring in Economics of between 514 and 765 percent compared to the mean value, suggesting that this change is substantial.

Regarding majoring in the Social Sciences, we estimate that meeting the qualifications to transfer through the CAP increases the likelihood of major in the Social Sciences between 6 and 10 percentage points. The LATE estimates suggest that transferring through the CAP is associated with an increase in the likelihood of majoring in the Social Sciences of between 15 and 43 percentage points. These results are consistently large and statistically significant across all bandwidths. Our LATE results suggest an increase in the probability of majoring in the Social Sciences of between 170 and 350 percent relative to the mean value of the counterfactual, suggesting that this change is economically substantive.

Looking at Engineering majors, our ITT estimates suggest that access to the opportunity to transfer through the CAP is associated with a change in the likelihood of majoring in Engineering of between -2 and 1 percentage points. The LATE estimates range from -7 to 2 percentage points. We interpret these estimates as imprecisely measured zeros, none of which are statistically significant. The estimated coefficients are fairly consistent in terms of sign across our larger (greater than .25) bandwidths, and are small in terms of magnitude across these bandwidths, with effect sizes for our LATE estimates being between 30 and 32 percent of the mean value (at the smallest bandwidth or 0.10 , the magnitude of our coefficient is 246 percent of the mean value), suggesting that there is little to no impact of 
the CAP on the probability of majoring in Engineering.

With respect to Business majors, our ITT estimates suggest that the CAP transfer option is associated with a decrease in the likelihood of majoring in business of between 3 and 8 percentage points. The LATE estimates indicate that CAP transfers are between 12 and 22 percentage points less likely to major in business, relative to their counterfactual. Our results are statistically significant at our larger bandwidths (0.30 and above) and are consistent in terms of their sign across all of our bandwidths. Our LATE estimates are between 74 and 109 percent of the control group mean, suggesting an economically substantive impact of the CAP on the probability of majoring in Business.

We estimate that having the opportunity to transfer through the CAP is associated with an increase in the likelihood of majoring in communications of between 2 and 4 percentage points. Our LATE estimates suggest that for CAP transfers, the likelihood of majoring in communications increases by between 8 and 12 percentage points. Although these results are statistically significant only at our largest bandwidth, they are fairly consistent in terms of sign and magnitude across all bandwidths. Our LATE estimates suggest that the CAP is associated with an increase in the probability of majoring in communications of between 98 and 149 percent relative to the control group mean, suggesting that the magnitude of this effect is fairly large and economically substantive.

Regarding Math and Science majors, our ITT estimates indicate that the CAP transfer option is associated with a decrease in the likelihood of majoring in Math or Science of at most 4 percentage points. Our LATE estimates suggest that for CAP transfers, the likelihood of majoring in Math or Science decreases by between 1 and 12 percentage points. Although these results are only statistically significant at our largest bandwidth, they are consistently negative across all bandwidths. Our LATE estimates suggest a decrease in the probability of majoring in Math and Science of between 1 and 150 percent; excluding the 0.25 bandwidth, these estimates indicate an effect size of around 80 percent fairly consistently, suggesting some imprecision with regards to our estimates, but also that this treatment effect could be 
fairly large.

For all other majors, our ITT estimates suggest that having the CAP transfer option is associated with a decrease in the likelihood of attaining these majors of between 1 and 10 percentage points, while our LATE estimates indicate that for CAP transfers, the likelihood of majoring in these fields decreases by between 1 and 35 percentage point. These results are statistically significant among our middle bandwidths (0.25 and 0.30$)$, and are consistent in terms of their magnitude across bandwidths between 0.10 and 0.45 . Our late estimates suggest a magnitude of between 67 and 82 percent of the control group mean for our smaller bandwidths, and a magnitude of 1 percent at a bandwidth of 0.50 , indicating that the CAP leads to a fairly large and economically substantive decrease in the probability of majoring in Other majors at our smaller bandwidths, but that this effect dissipates when our bandwidth becomes sufficiently large (greater than around 0.30).

Taken together, these results suggest that at smaller bandwidths, CAP transfer students are much less likely to major in Business, Engineering, Math or Science, and Other Majors at The University of Texas at Austin relative to their peers at CAP participating institutions. We also find that CAP transfer students seem to instead major in subjects like Economics, Social Sciences, and Communications. At our larger bandwidths, Students appear to be less likely to major in Business and Math or Science and more likely to major in Economics, Social Science, and Communications, with no real impact in the probability of majoring in Engineering or Other Majors.

\subsection{Financial Aid}

Table 9, reports the impact of the CAP on students' financial aid package. We present these results in two different ways. First, we present estimates of the likelihood of receiving the various financial aid components. Second, we present estimates of the dollar amounts of the various financial aid components, conditional on receipt of those components.

We estimate that access to the option to transfer via CAP transfer changes in the like- 
lihood of receiving a scholarship by -0.07 to 6 percentage points. The LATE estimates range from -.2 to 29 percentage points. Our results are not statistically significant at any bandwidth. Moreover, the sign of the estimated effects is inconsistent across bandwidths. Our LATE estimates suggest a magnitude around 114 percent at our smallest bandwidth and magnitudes between 1 and 17 percent for our other bandwidths. We interpret the estimates to be fairly imprecise at the 0.10 bandwidth and economically insignificant at other bandwidths.

Conditional on having received a scholarship at one's last institution, we find that access to CAP transfer option increases scholarship awards by 917 to 1, 426 dollars and that transfer via CAP increases the scholarship amount by 2,882 to 3,626 dollars. These results are statistically significant across nearly all of our bandwidths and are consistent with regards to sign. The magnitude of the LATE estimates range between between 1.29 and 1.97 standard deviations above the mean value across our other bandwidths. Taken together, our estimates show that students who transfer to The University of Texas at Austin due to just qualifying for the option to do so are no more likely to receive a scholarship than students at CAP participating institutions; however, transfers do receive considerably more scholarship funds.

Similar to the results for scholarship receipt, we find no evidence of a difference in the likelihood of receiving a grant. The ITT estimates indicate that the availability of the option to via the Coordinated Admissions Program increases the likelihood of receiving a grant by 1 to 5 percentage points, and the LATE estimates range grom 2.7 to 23 percentage points. None of the estimates achieve statistical significance.

However, we do find that the Coordinated Admissions Program has an impact on the amount of grant funding that is received. The availability of the option to transfer via the CAP leads to an increase in the amount of grant awards that ranges between 1,456 and 1, 901 dollars for grant recipients. The LATE estimates show that an increase between 4,559 and 7,590 dollars for students who transfer to The University of Texas at Austin due to just qualifying for the option to transfer via the CAP. These results are statistically significant 
across most of our bandwidths (between 0.25 and 0.50 ). From our LATE estimates, we find that these coefficients represent an increase of between 1.37 and 2.34 standard deviations above the mean value, suggesting a large impact of the CAP on Grant dollars received.

We find some evidence that that the Coordinated Admissions Program is related to the likelihood of taking out a student loan. The ITT estimates suggest that access to the CAP transfer option decreases the likelihood of having a student loan from 1 to 7 percentage points. For CAP transfers, we estimate that the likelihood of having a student loan decrease between 2 and 32 percentage points which corresponds to a decrease of 74 percent for our smallest bandwidth to 4 percent at our largest bandwidth. Our results are statistically significant for the 0.15 and 0.20 bandwidths and consistent with regards to sign across all bandwidths.

Given that a student takes out a student loan, we estimate that access to transfer via the CAP induces a change in the amount of loans that varies from a decrease of 275 dollars to an increase of 30 dollars. Our LATE estimates range from a decrease of 851 dollars to an increase of 129 dollars. These estimates are inconsistent with regards to direction across bandwidths and never achieve statistical significance. We interpret these estimates as evidence that neither the option to transfer via the CAP nor actually transferring to The University of Texas at Austin due to the CAP influences student borrowing at the extensive and intensive margins.

Additionally, we look at changes in Cost of Attendance (COA) for the CAP. Our ITT estimates show a change in COA of between -51 and 348 dollars. Our LATE estimates indicate a change in COA of between -218 and 1,162 dollars. These estimates are consistent in sign at all but our smallest bandwidth, and are statistically significant at larger bandwidths. For our LATE estimates, this change in COA represents a decrease of 19 percent at a bandwidth of 0.10 , and between an 81 and 93 percent change in COA at our other bandwidths.

In summary, we find no evidence that suggests that CAP transfers are more or less likely 
to receive financial aid relative to their peers at CAP participating institutions. However, we do find compelling evidence that CAP transfers, conditional on receiving a scholarship or grant, do receive larger amounts of both scholarships and grants. We also find that CAP transfers face a higher COA, but that this increase is smaller in magnitude than the changes in grants and scholarships.

\section{Conclusion}

The issue of access to oversubscribed public universities has been the focus of considerable legal, political, and economic study. And with good reason, the decision of where to go to college is one of the most important decisions that students and families face. There is considerable evidence that finds that higher quality public colleges are associated with better academic and labor market outcomes. The University of Texas at Austin has been at the forefront of much of the access debate and is representative of the issues that oversubscribed public universities face. Therefore, the findings of this paper are useful for public universities that constantly deal with the thorny task of balancing accessibility with the need to ration slots due to an excess supply of potential attendees.

The University of Texas at Austin's response to increased demand for undergraduate admission was to create an alternative pathway that allowed Texas residents to transfer to The University of Texas at Austin if they met certain performance criteria. Regular admissions to UT-Austin is competitive. Student applications are not independent; that one student gets admitted has some impact on the likelihood that other students are admitted. The Coordinated Admissions Program, however, provides a set of transparent requirements for the option to transfer to The University of Texas at Austin from CAP participating

institutions, and the availability of the option does not directly depend on the efforts of other students. The structure of the program is suitable for the regression discontinuity design. We estimate the causal effect of access to The University of Texas at Austin for 
marginal students who complied with the availability of the option to transfer.

We show that this is a new path and that students have responded to its creation by taking it up. Long and Tienda (2010) find that the distribution of SAT Test Scores improved for some of the participating University of Texas System schools. They argue correctly that some of the shift is due to students with high scores and lower class ranks opting to go to a less selective institution following the passage of The Top Ten Percent Rule. We contend that some of the shift in the distribution of test scores is due to the enrollment of CAP students who must begin their college careers at the satellites but do not intend to remain at those institutions to complete their studies.

We find evidence that Transferring to Austin has a positive impact on earnings. We find no evidence of systematic differences in four-, five-, and six-year graduation rates. We do see a negative impact on cumulative grade point average. Our results show that CAP students experience a sizable increase in scholarship and grant amounts but no significant differences in loans, and an increase in Cost of Attendance that is smaller than the increases in grants and scholarships, which suggests for marginal transfer students to The University of Texas at Austin, the financial aid package they receive is more generous with regards to grants and scholarships, compared to the packages that their counterfactuals receive at participating system schools.

The impact of transferring to The University of Texas at Austin on the choice of major is striking. Marginal transfer students are more likely to major in economics and social sciences, but less likely to major in business. Students who take advantage of the Coordinated Admissions Program are allowed limited choices with regards to choice of major. CAP students are allowed any major in The University of Texas at Austin's School of Liberal arts. Students can attempt to major in more competitive subjects; however, they are not guaranteed admission. Indeed, the website that explains the CAP program to prospective students states that if students are interested in particularly competitive majors, then they 
should consider going to another school where that major is accessible. ${ }^{13}$ The undergraduate business major at The University of Texas at Austin is highly competitive. The decision for students to opt to major in the social sciences and economics is reasonable as these majors are, perhaps, a substitute for business. We find some evidence that transfer to The University of Texas at Austin is associated with a decline in the likelihood of majoring in STEM. Marginal transfer students certainly major in different things; however, these students have neither seen a decrease in the likelihood of completion nor suffered with regards to labor market performance. Although students who transfer to The University of Texas at Austin attend an higher quality institution, they finish in majors that provide smaller predicted returns ${ }^{14}$, but the net effect of the major and school change seems to be positive, suggesting that the drop in predicted earnings associated with worse performing majors seems to be offset by the predicted earnings premium associated with attending The University of Texas at Austin.

The Coordinated Admissions Program shows that differences in institutions, broadly speaking, have an impact on the student choices and success. The CAP is a means of gaining access to The University of Texas at Austin, but not necessarily to the full suite of educational opportunities it provides. Despite marginal transfer students having limited options, they have done as least as well as their counterparts that remain at the satellites. Still, we should be cautious, if students derive non-pecuniary benefits from having access to particular majors, then our results understate the impact on overall student well-being. Our study of the Coordinated Admissions Program suggests that any discussion of alternative paths to access a particular University must also explicitly consider the implications for student choices.

\footnotetext{
${ }^{13}$ Information retrieved from The University of Texas at Austin's Office of Admissions website for prospective CAP students on April 10, 2017. Web address:https://admissions.utexas.edu/enroll/cap/ prospective-students

${ }^{14}$ Here, looking at major ranking as in Arcidiacono (2004)
} 


\section{References}

Andrews, R., J. Li, and M. F. Lovenheim (2014). Heterogeneous paths through college: Detailed patterns and relationships with graduation and earnings. Economics of Education Review 42, $93-108$.

Andrews, R. J. (2016, May). Coordinated admissions program. American Economic Review $106(5), 343-47$.

Andrews, R. J., J. Li, and M. F. Lovenheim (2016). Quantile treatment effects of college quality on earnings. Journal of Human Resources 51(1), 200-238.

Arcidiacano, P., E. M. Aucejo, and V. J. Hotz (2016). University differences in the graduation of minorities in stem fields: Evidence from cali- fornia. American Economic Review 106 (3), 525-562.

Arcidiacono, P. (2004). Ability sorting and the returns to college major. Journal of Econometrics 121(12), 343 - 375. Higher education (Annals issue).

Arcidiacono, P. (2005). Affirmative action in higher education: How do admission and financial aid rules affect future earnings? Econometrica 73(5), 1477-1524.

Arcidiacono, P. and M. Lovenheim (2016, March). Affirmative action and the quality-fit trade-off. Journal of Economic Literature 54(1), 3-51.

Barreca, A. I., J. M. Lindo, and G. R. Waddell (2016, 01). Heaping-Induced Bias In Regression-Discontinuity Designs. Economic Inquiry 54(1), 268-293.

Black, D., J. Smith, and K. Daniel (2005). College quality and wages in the united states. German Economic Review 6(3), 415-443.

Black, D. A. and J. A. Smith (2006). Estimating the returns to college quality with multiple proxies for quality. Journal of Labor Economics 24(3), 701-728. 
Bound, J., M. F. Lovenheim, and S. Turner (2010, July). Why have college completion rates declined? an analysis of changing student preparation and collegiate resources. American Economic Journal: Applied Economics 2(3), 129-57.

Bound, J., M. F. Lovenheim, and S. Turner (2012, September). Increasing Time to Baccalaureate Degree in the United States. Education Finance and Policy 7(4), 375-424.

CAP Report 1 (2003, November). An Investigation Into the Performance of Students Attending The University of Texas at Austin as a Result of the Coordinated Admissions Program (CAP). Technical report, The University of Texas at Austin, Office of Admissions.

Cohodes, S. R. and J. S. Goodman (2014, October). Merit aid, college quality, and college completion: Massachusetts' adams scholarship as an in-kind subsidy. American Economic Journal: Applied Economics 6(4), 251-85.

Hoekstra, M. (2009). The effect of attending the flagship state university on earnings: A discontinuity-based approach. Review of Economics and Statistics 91(4), 717-724.

Imbens, G. W. and J. D. Angrist (1994). Identification and estimation of local average treatment effects. Econometrica 62(2), pp. 467-475.

Jones, D. (2015, July). The economics of exclusion restrictions in iv models. Working Paper 21391, National Bureau of Economic Research.

Lee, D. S. (2008). Randomized experiments from non-random selection in us house elections. Journal of Econometrics 142(2), 675-697.

Lee, D. S. and T. Lemieux (2010, June). Regression discontinuity designs in economics. Journal of Economic Literature 48(2), 281-355.

Long, M. C. and M. Tienda (2010). Changes in texas universities applicant pools after the hopwood decision. Social Science Research 39(1), 48 - 66. 
McCrary, J. (2008). Manipulation of the running variable in the regression discontinuity design: A density test. Journal of Econometrics 142(2), 698 - 714. The regression discontinuity design: Theory and applications.

Texas Higher Education Coordinating Board (2013, September). Texas high school graduates in the top $10 \%$ of their classes found in texas public higher education, fall 2009-2012 cohorts.

The University of Texas System Board of Regents (2004). Provisional admission policy: Rule 40302. Technical report, The University of Texas Sytem Board of Regents. 


\section{$\begin{array}{ll}7 & \text { Figures }\end{array}$}

Figure 1: Transfers to The University of Texas at Austin over time

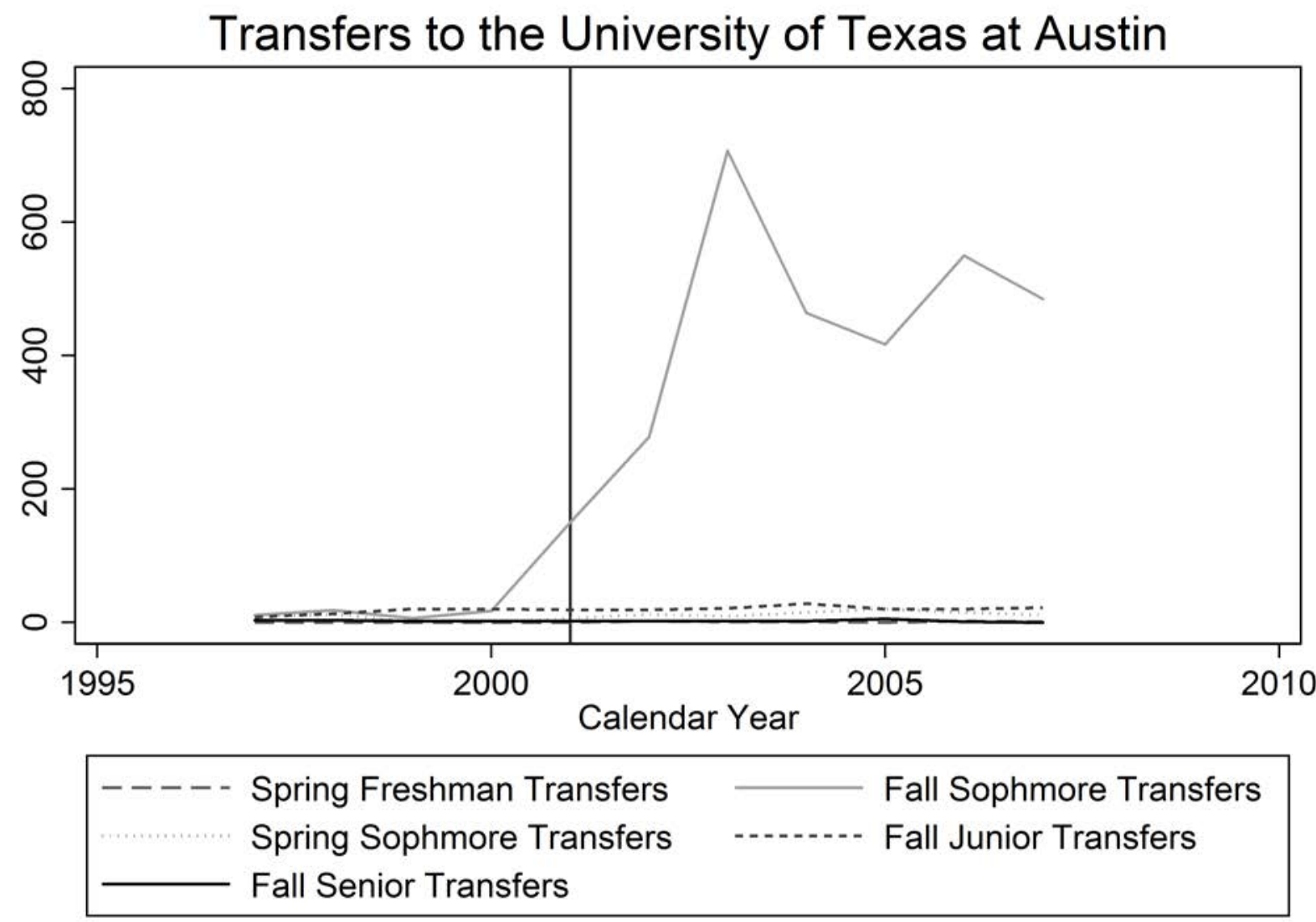


Figure 2: First Stage

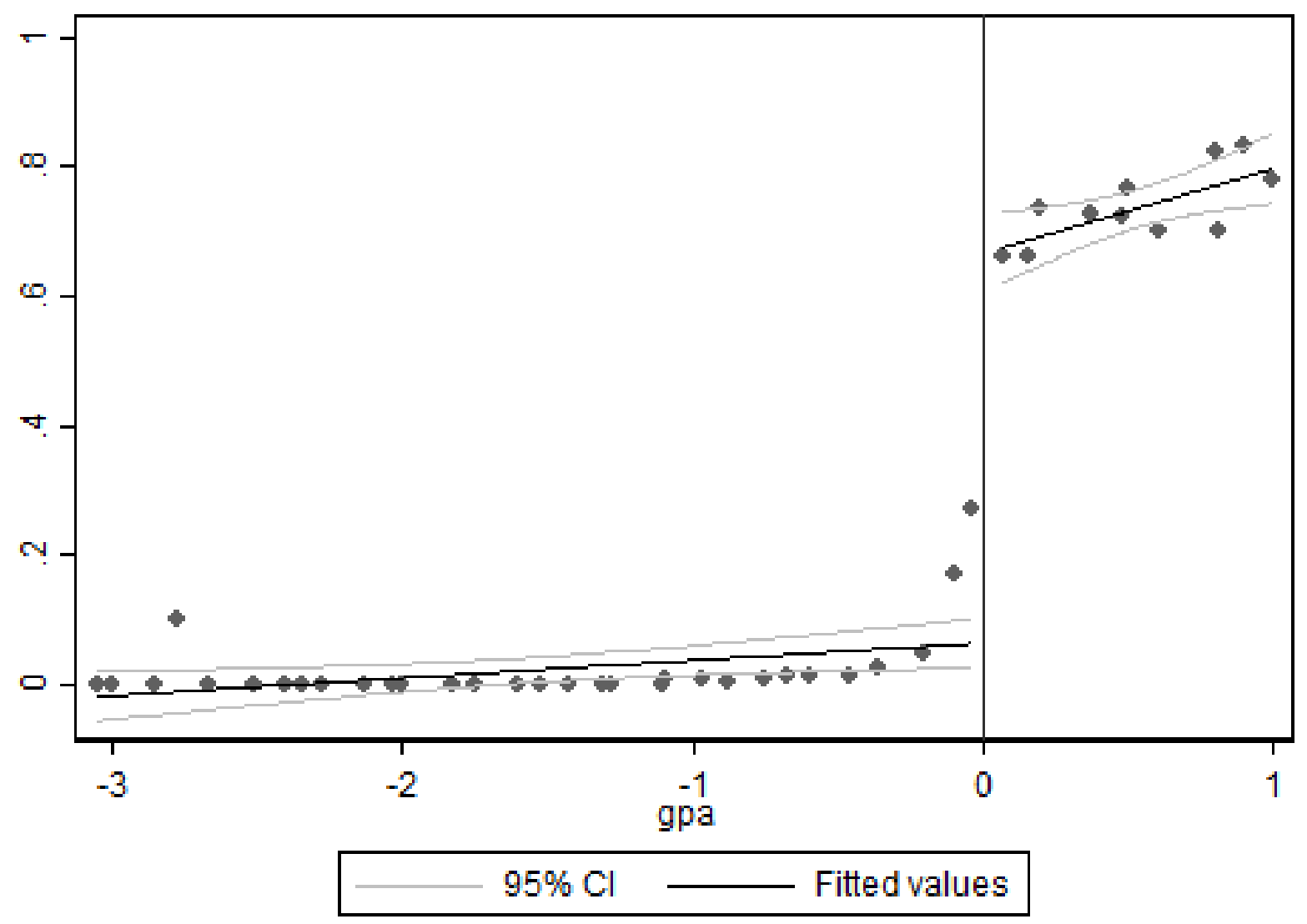


Figure 3: Balance - Math Exit Exam Score

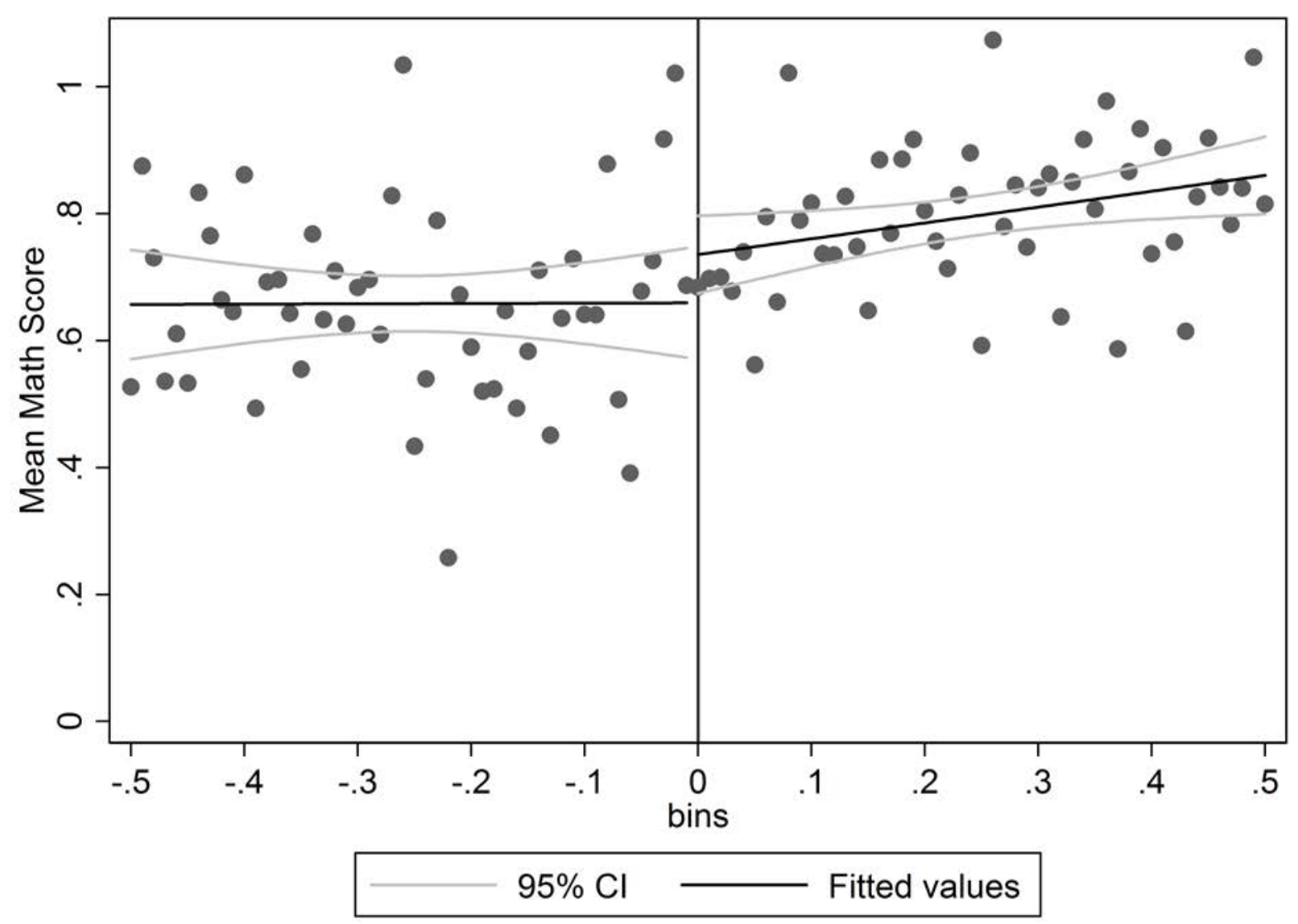


Figure 4: Balance - Reading Exit Exam Score

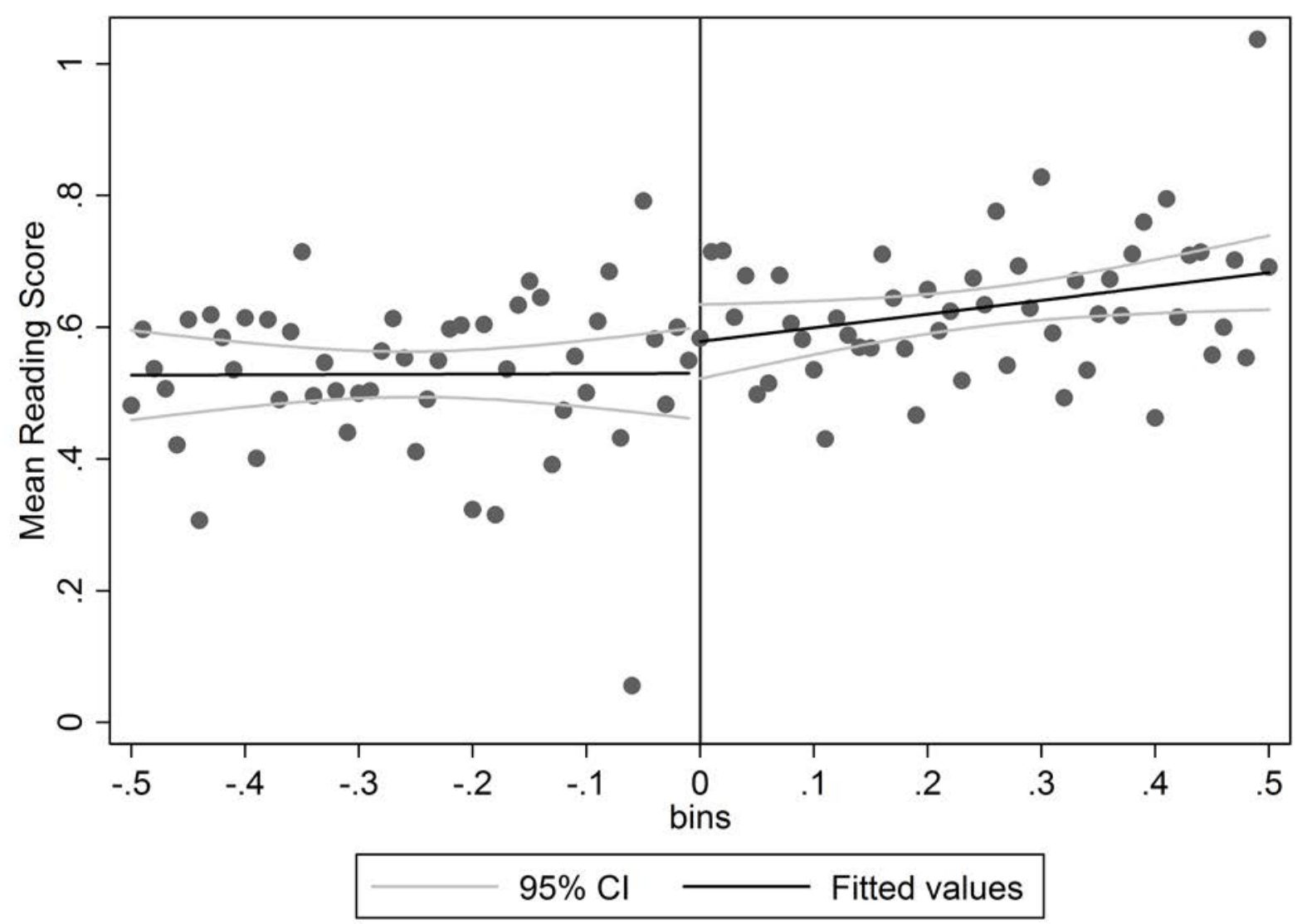




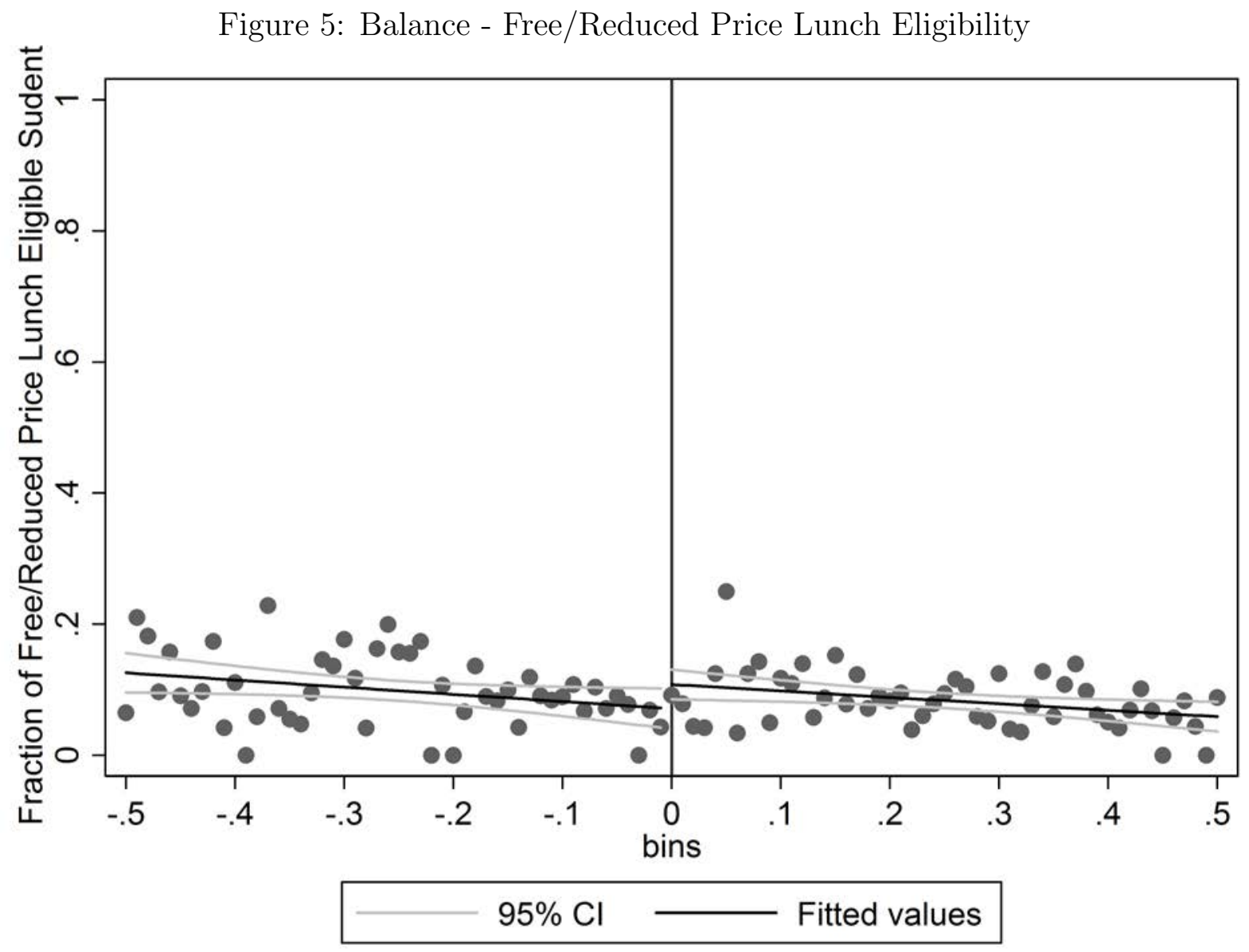


Figure 6: Balance - African American

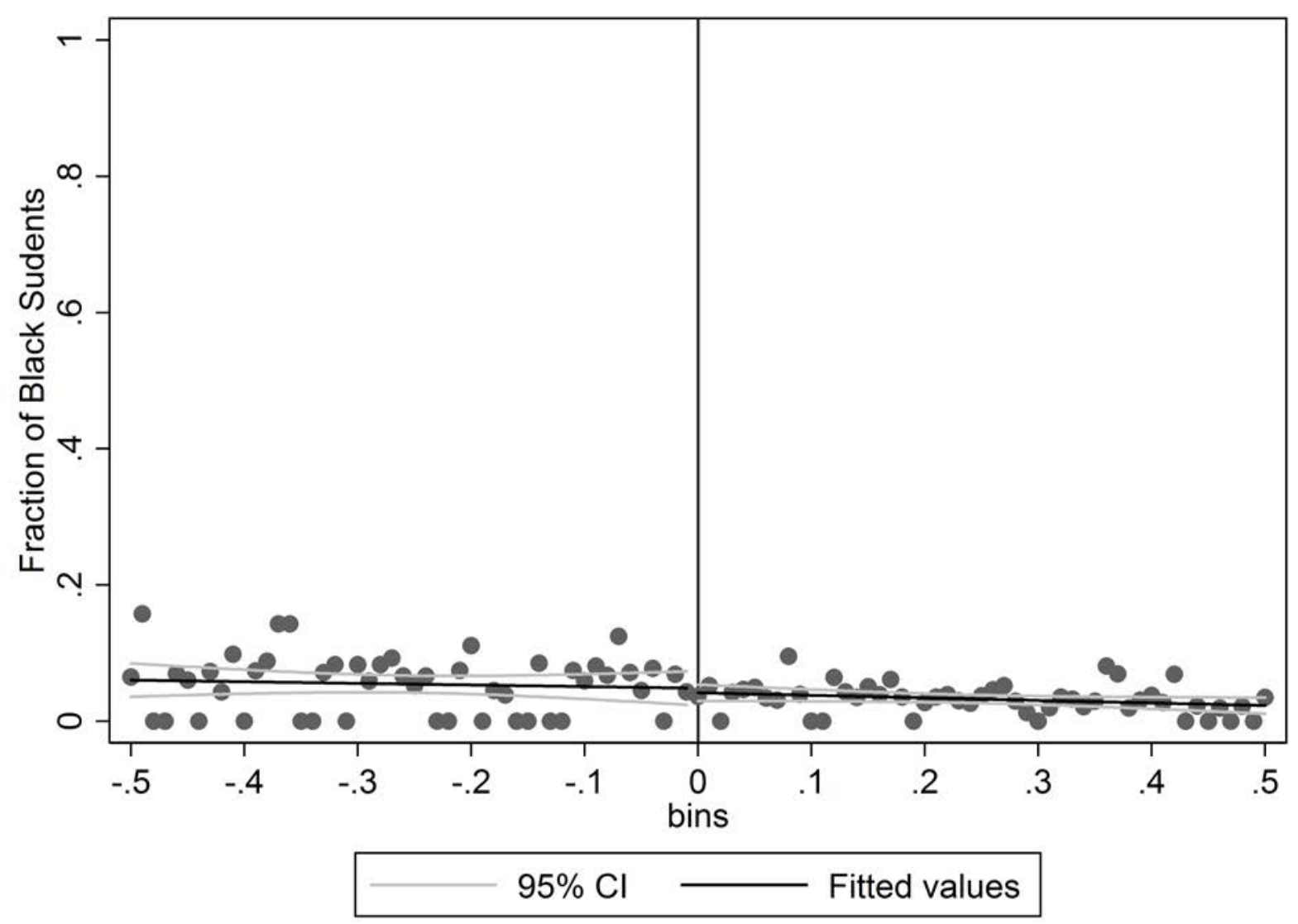


Figure 7: Balance - Asian

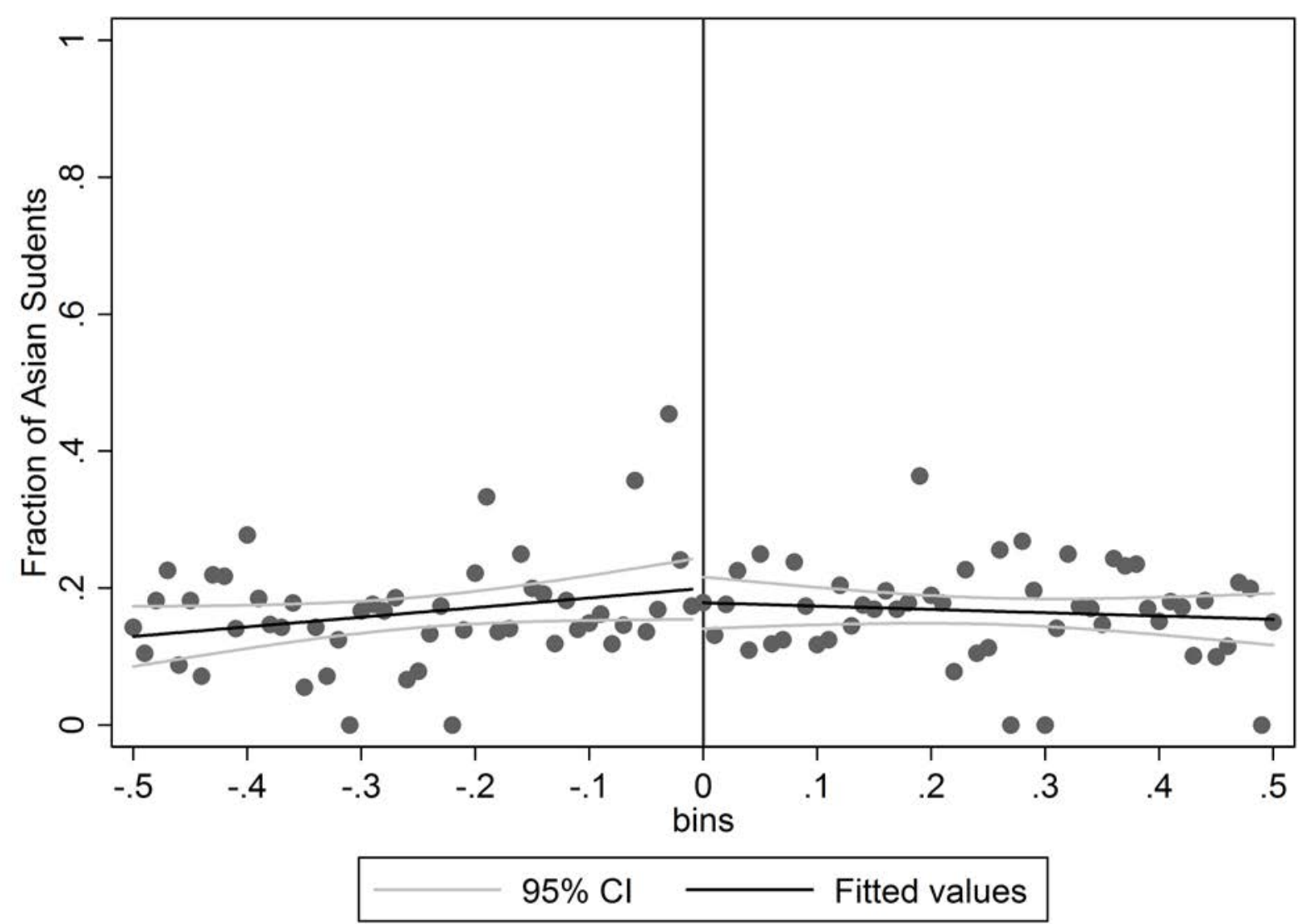


Figure 8: Balance - Hispanic

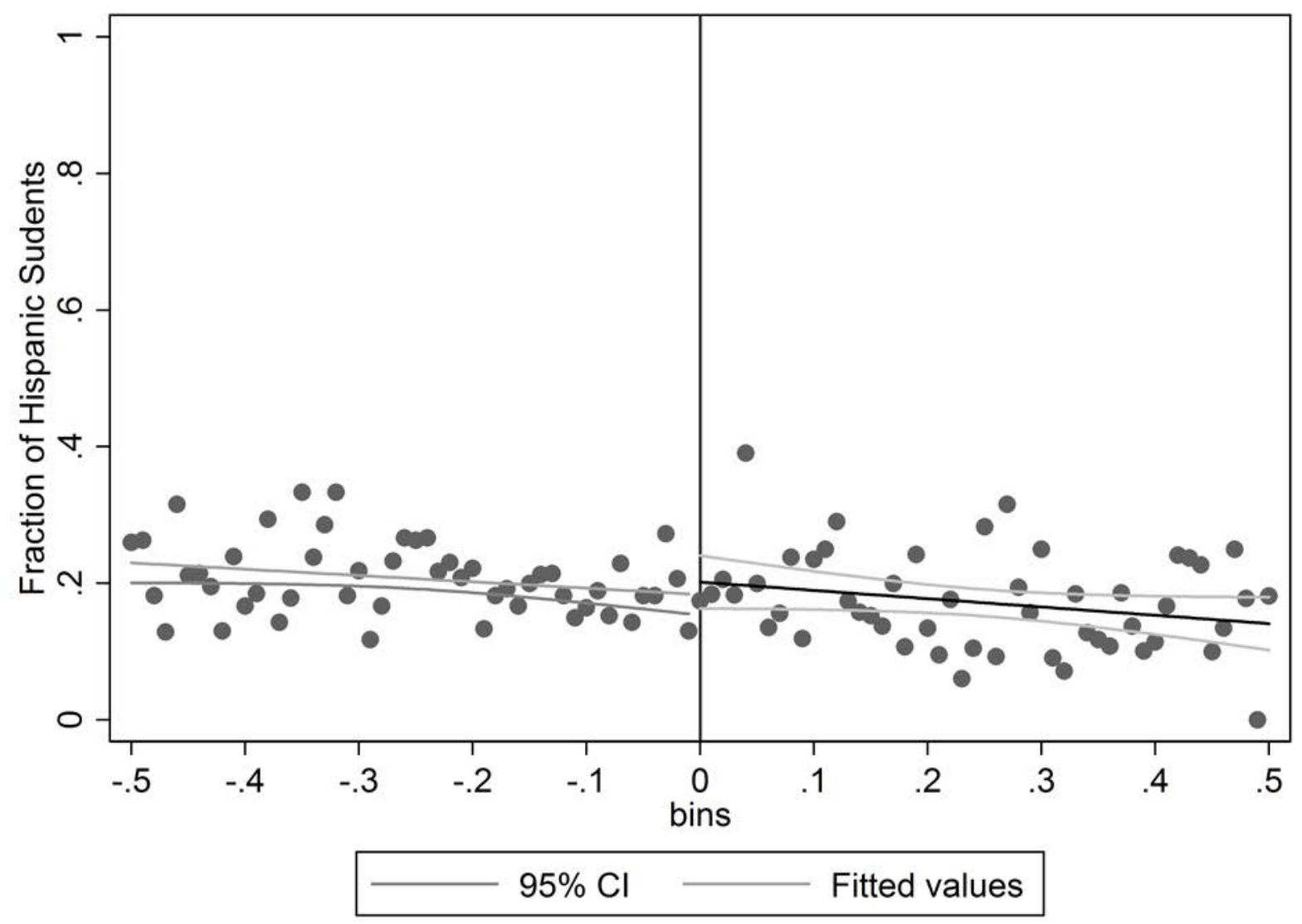


Figure 9: Balance - White

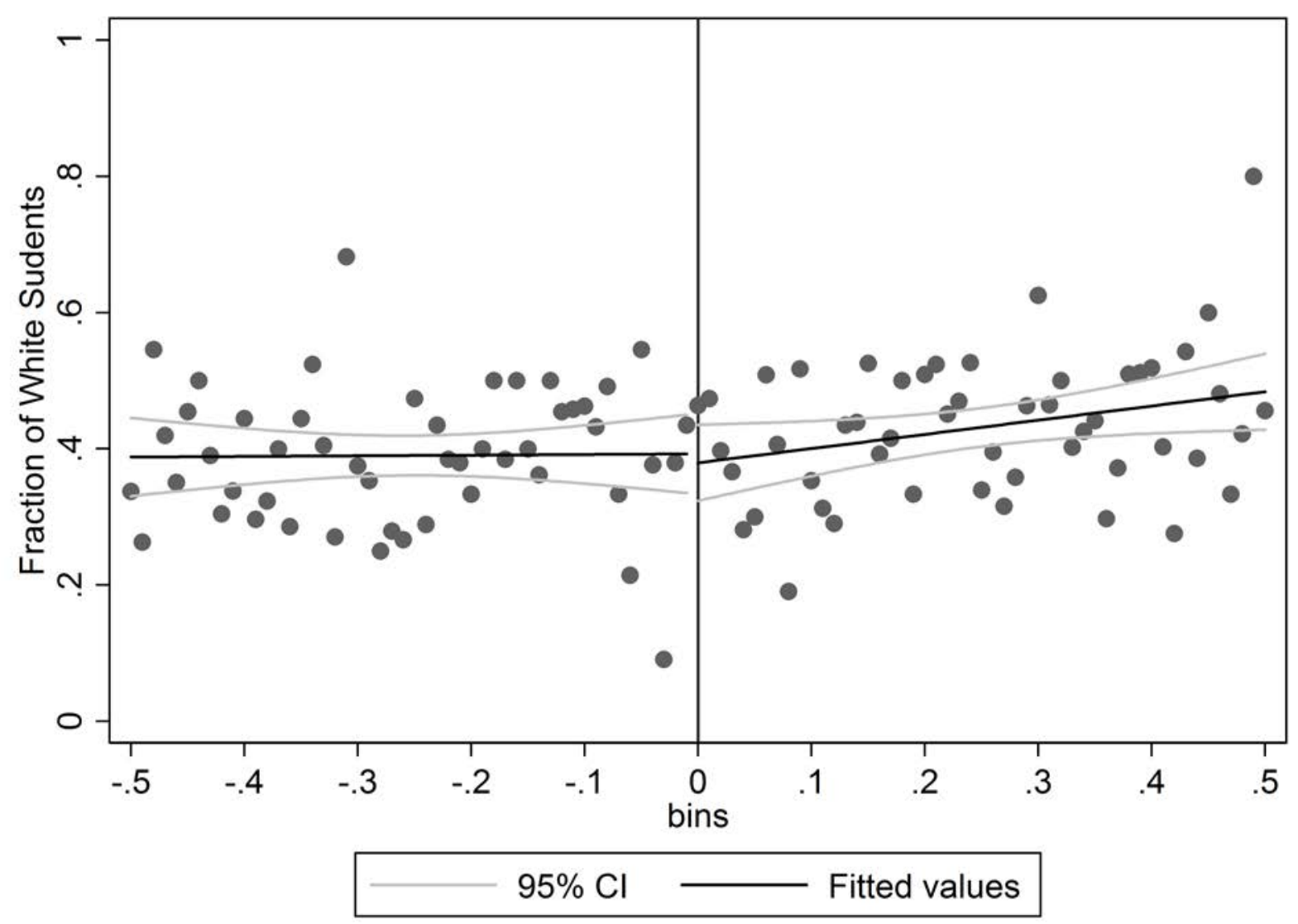


Figure 10: Balance - Other

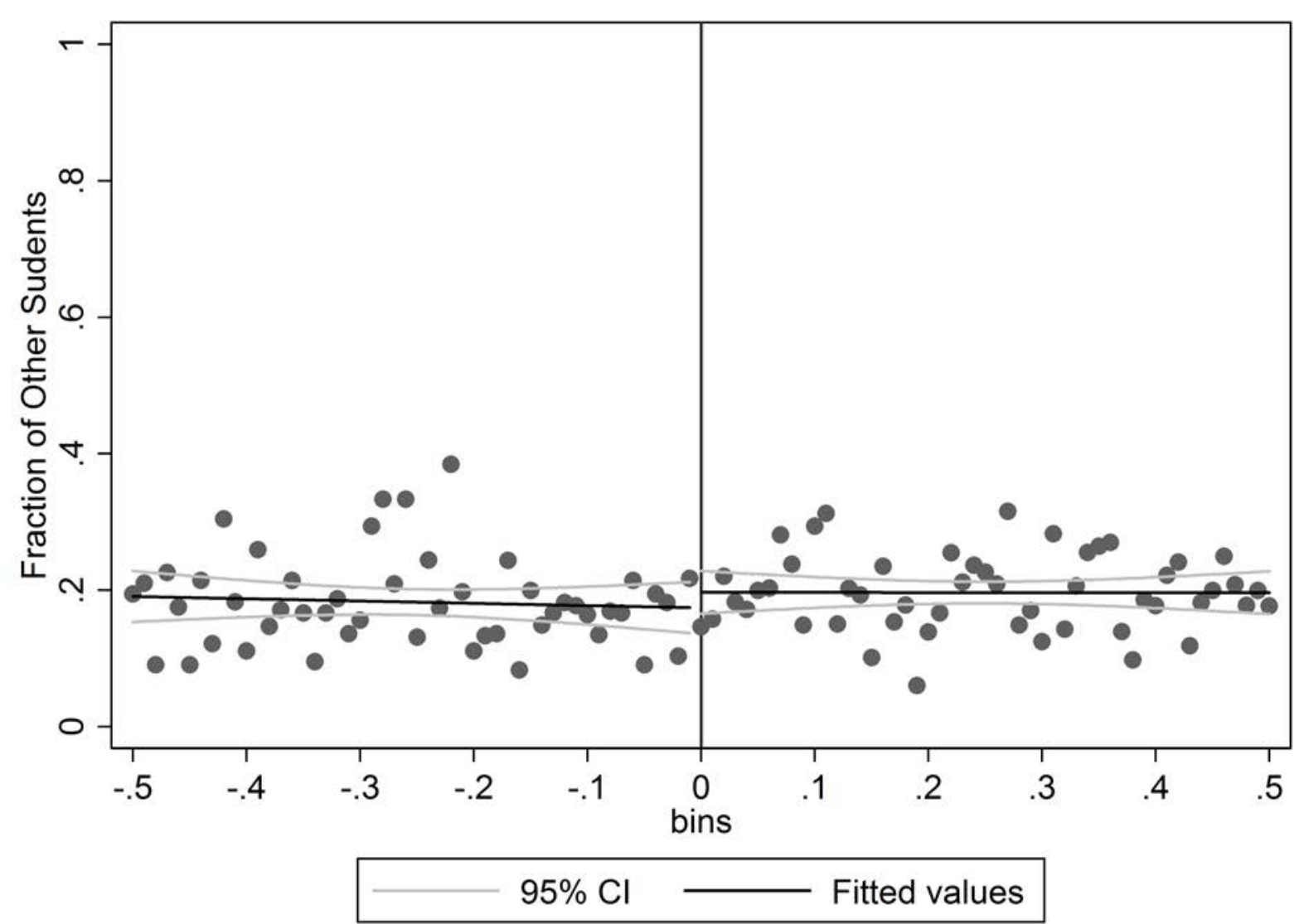


Figure 11: Balance - Male

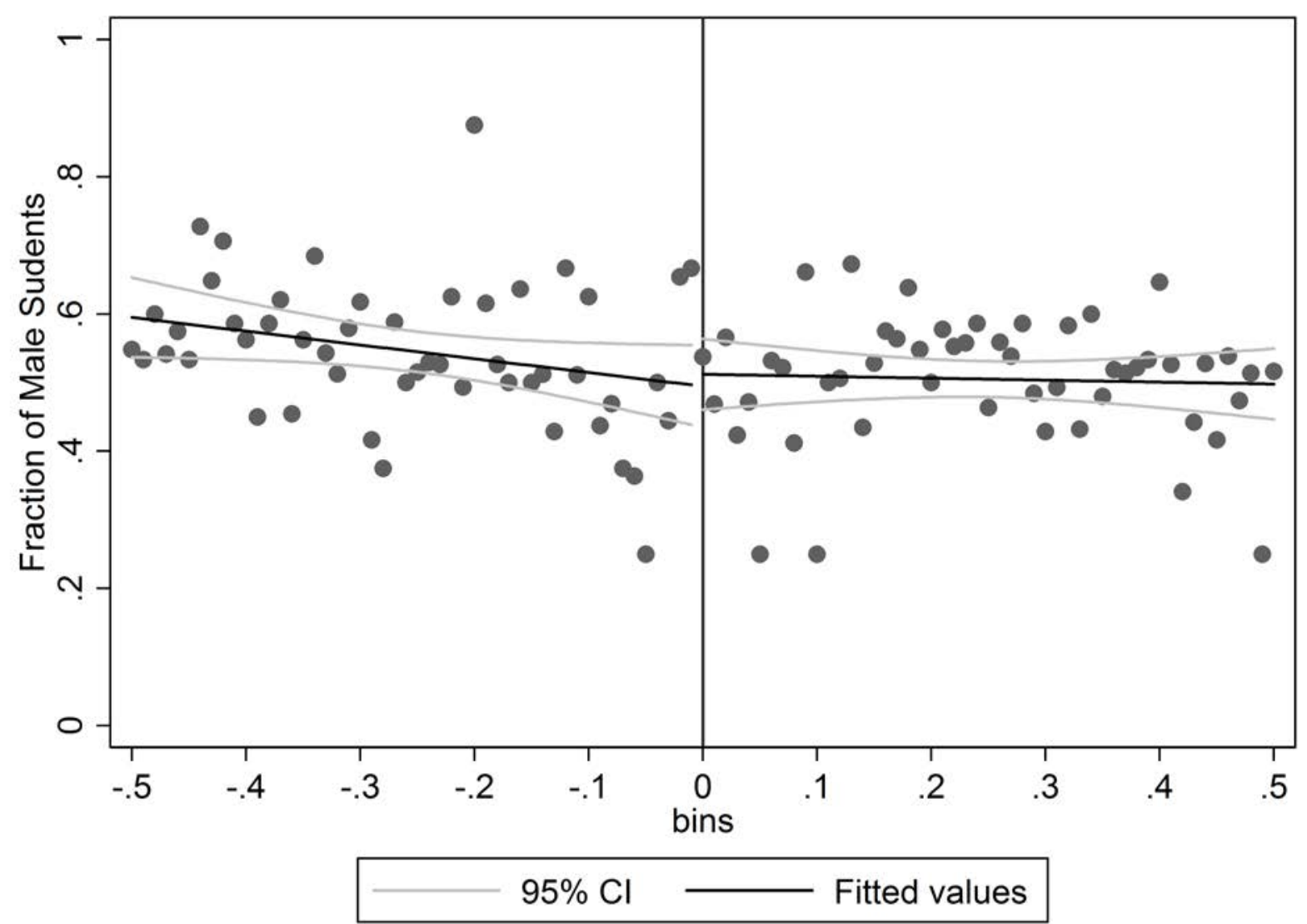


Figure 12: Balance - At Risk of Dropping out of High School

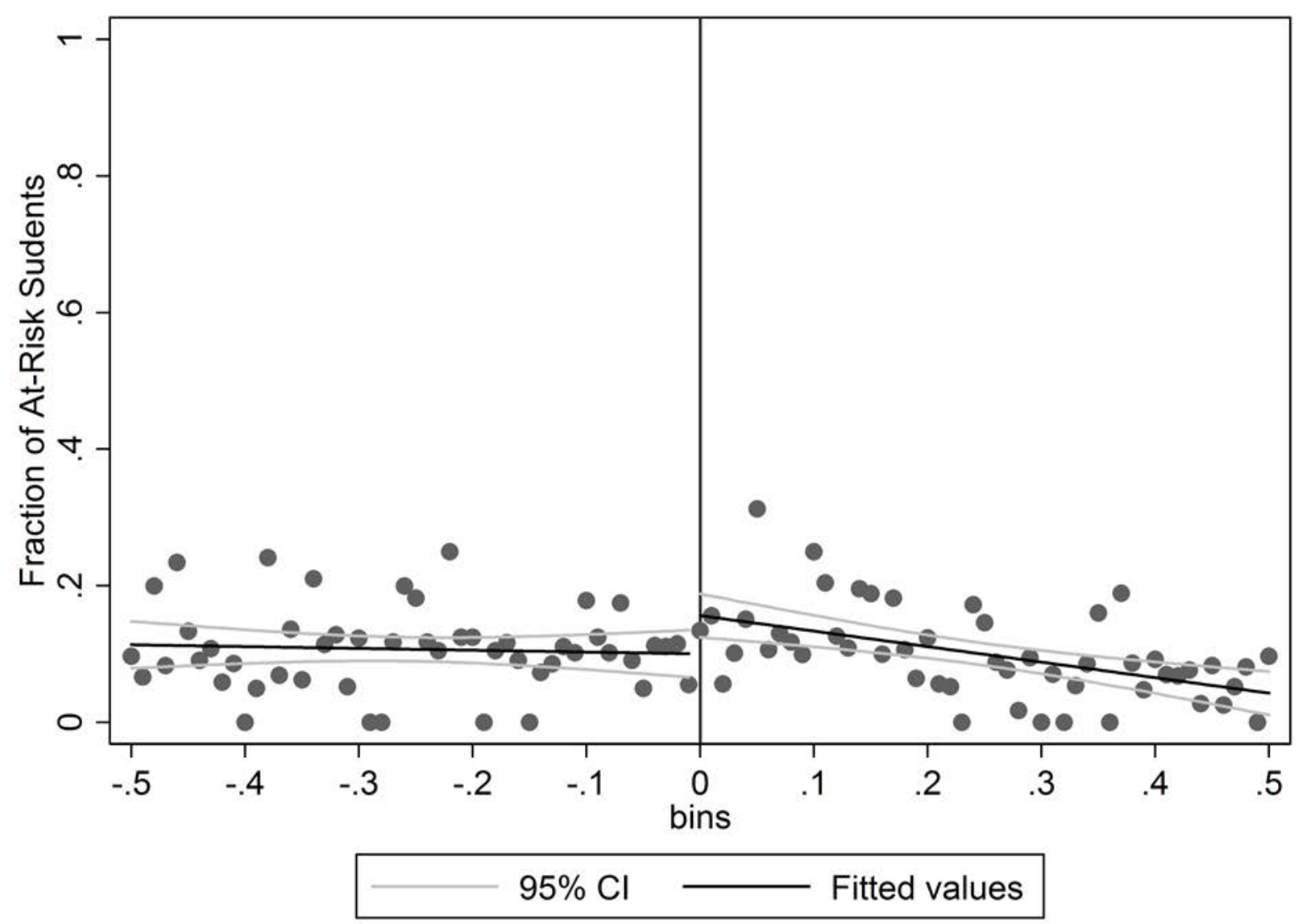


Figure 13: Balance - Gifted and Talented Status

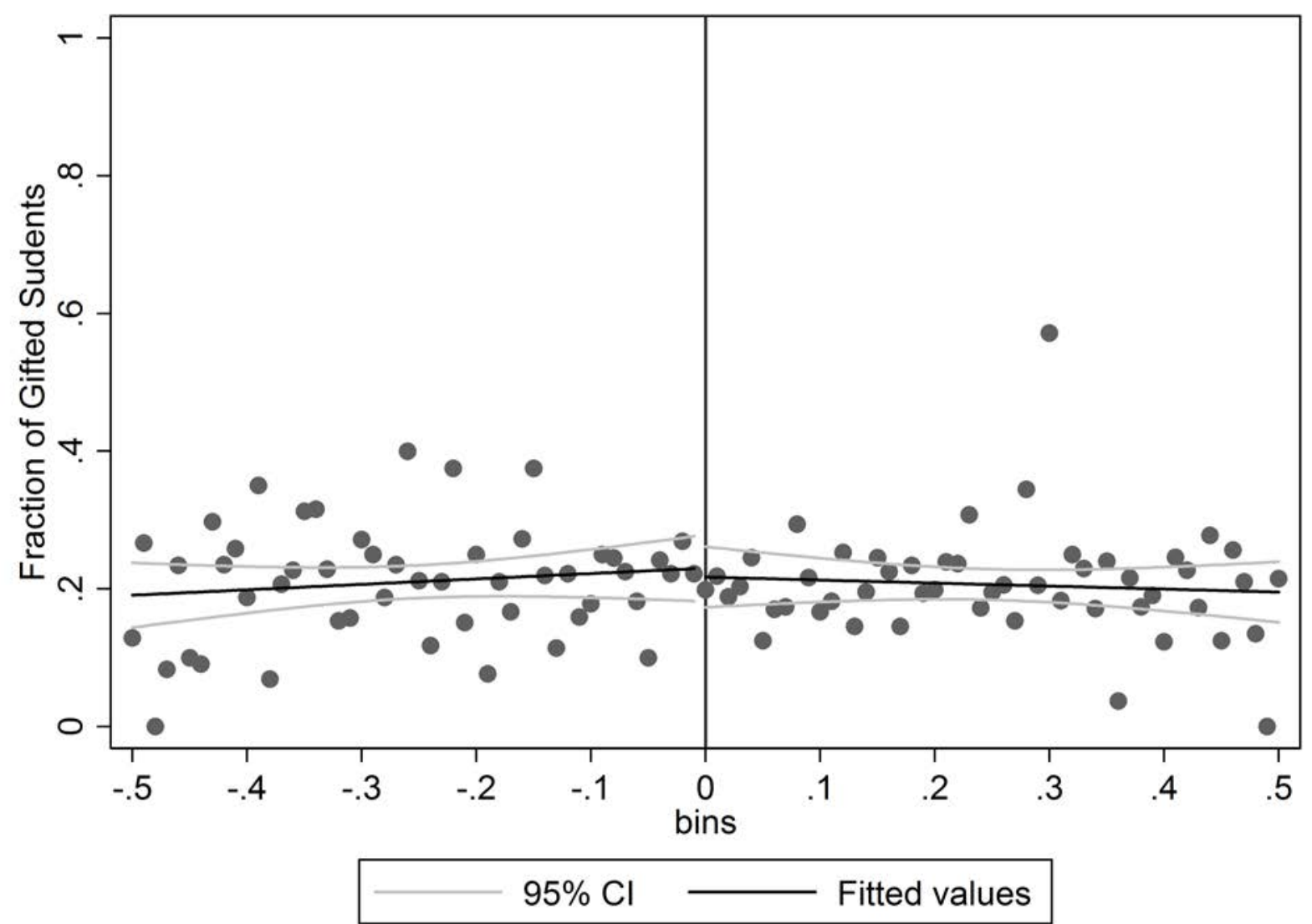


Figure 14: GPA Distribution Pre/Post CAP (Full Distribution)

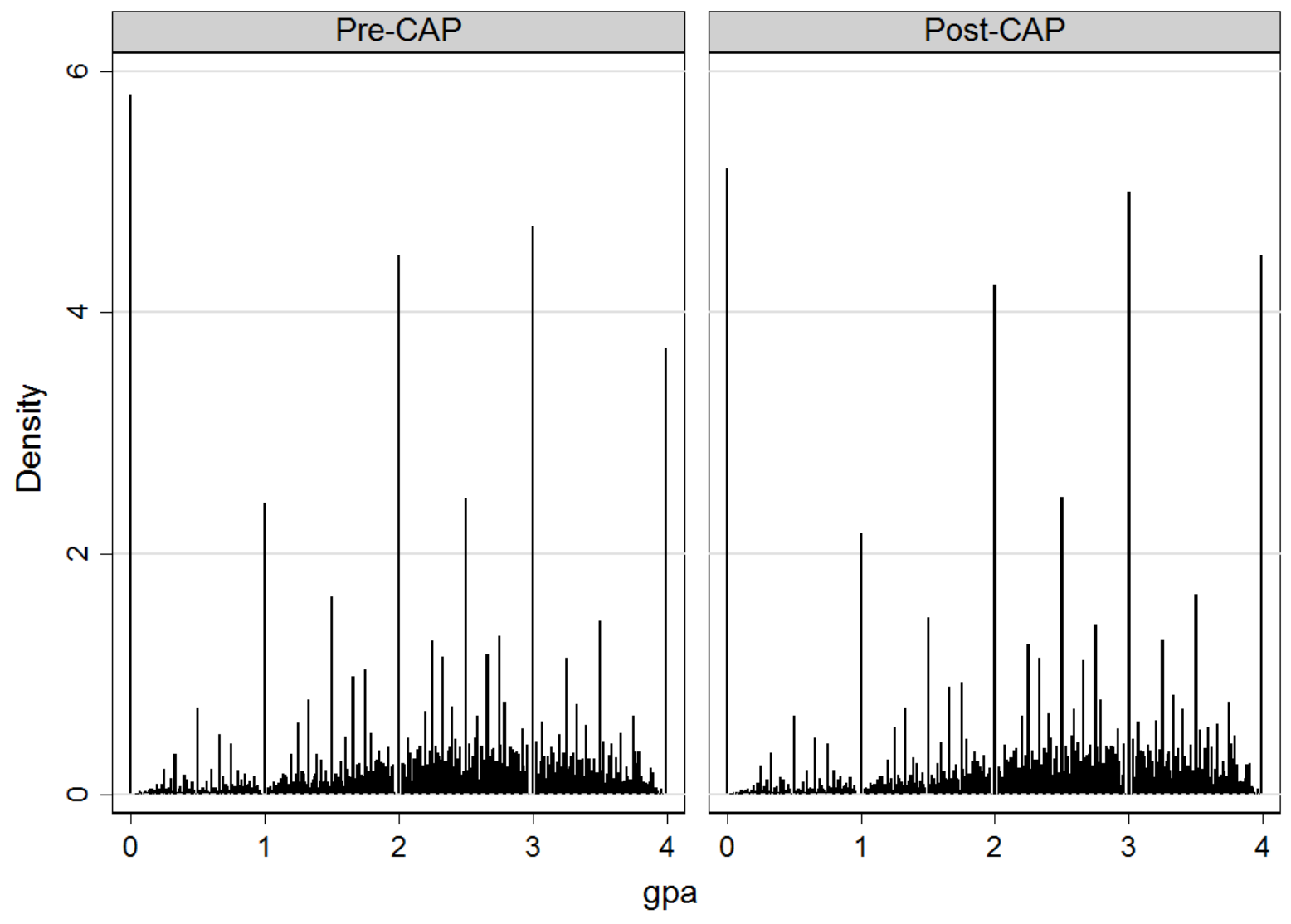


Figure 15: GPA Distribution Pre/Post CAP

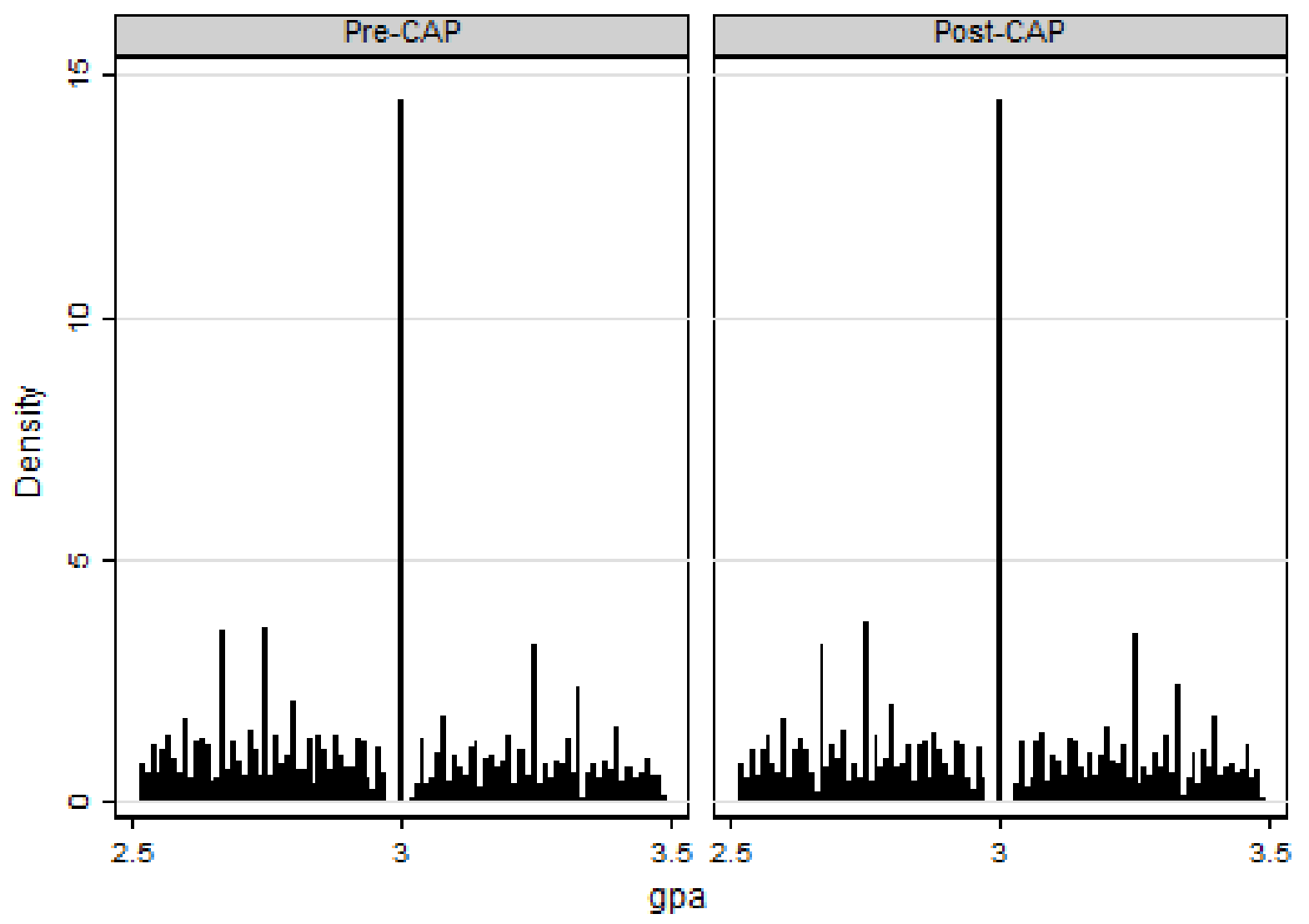


Figure 16: Transfers - Texas A\&M

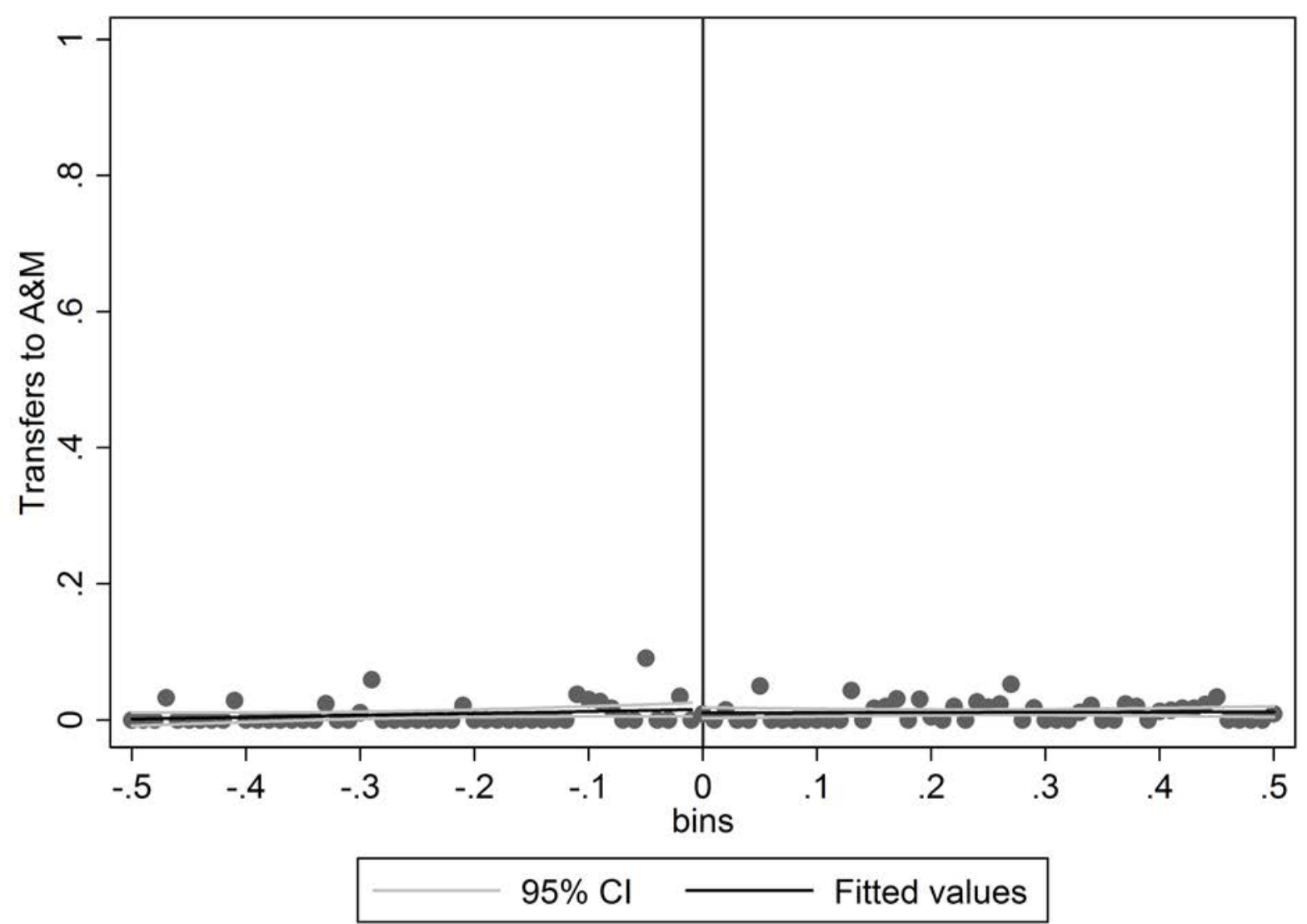


Figure 17: Transfers - Texas Tech University

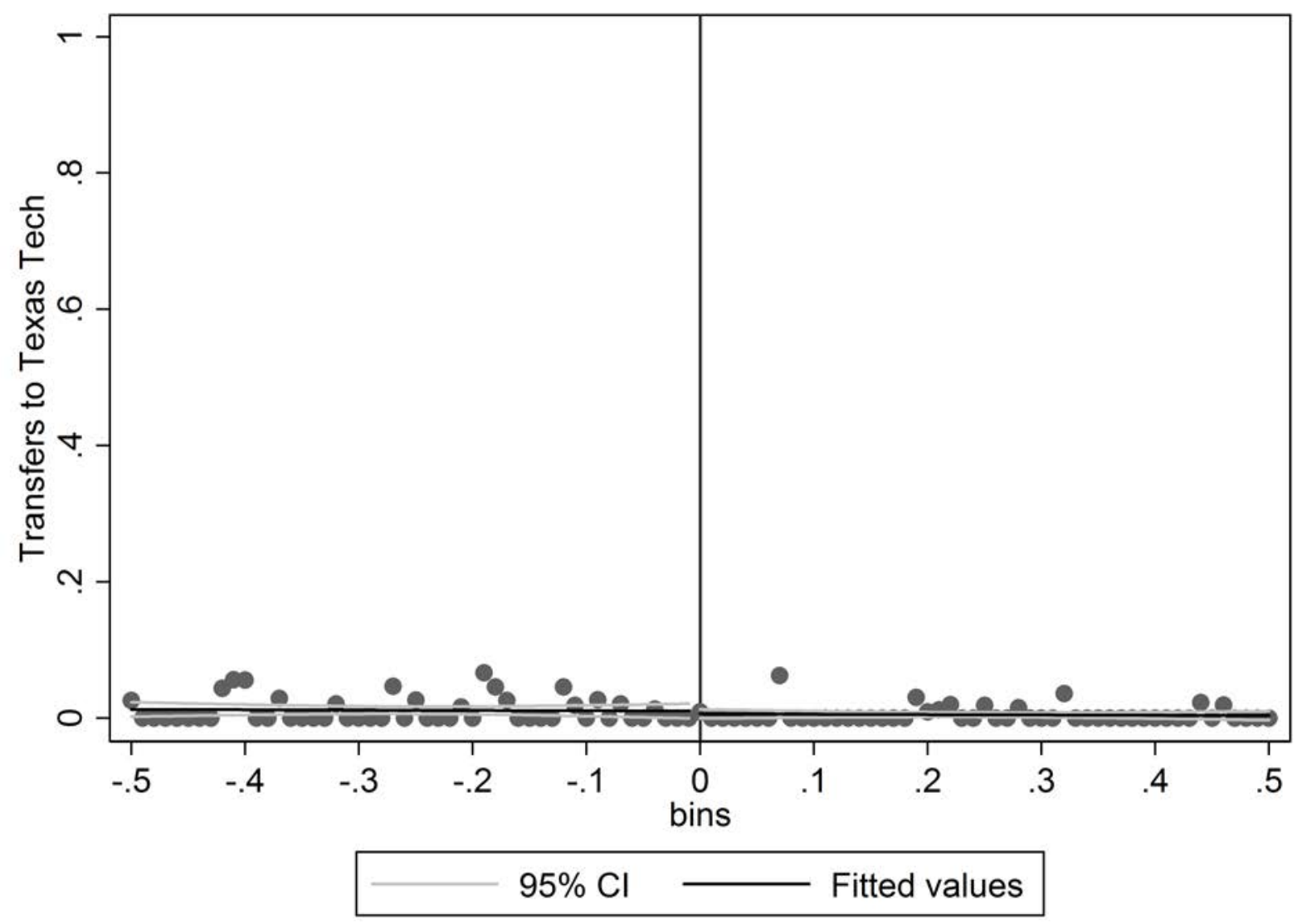


Figure 18: Transfers - University of Houston

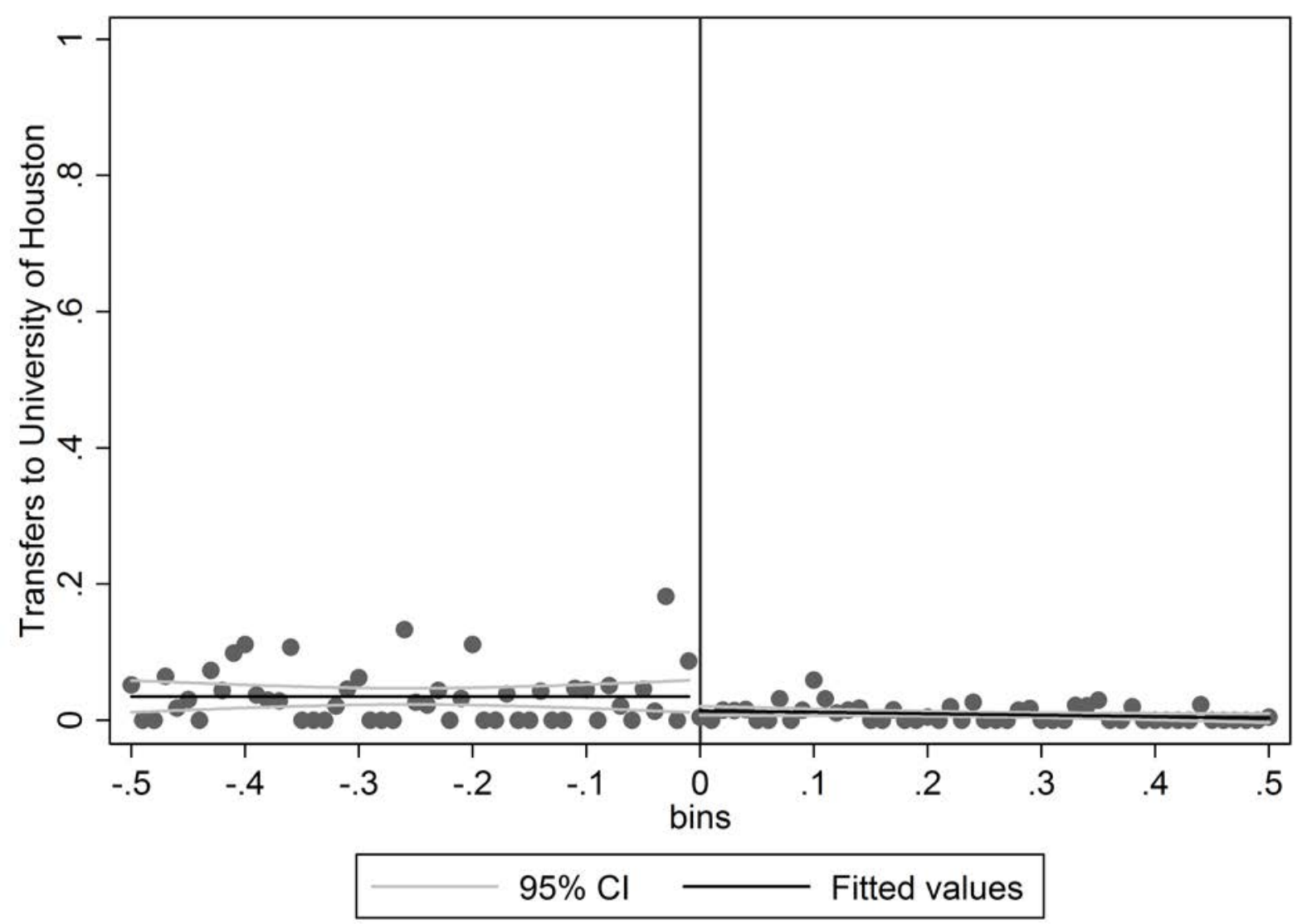




\section{Tables}

Table 1: Austin Compared to CAP-feeder schools

\begin{tabular}{lccc}
\hline & UT Austin & & CAP Feeders \\
Average Professor Salary - Male & 100269 & & 74012.5 \\
Average Professor Salary - Female & 89545 & & 70302.8 \\
Average Expenditure per Student & 6079.808 & & 2516.707 \\
6-year Graduation Rate & .702 & & .283 \\
Math SAT 25th percentile & 560 & & 456.621 \\
Math SAT 75th percentile & 680 & & 560.950 \\
Verbal SAT 25th percentile & 530 & & 457.614 \\
Verbal SAT 75th percentile & 650 & 552.988 \\
Fraction African American & .030 & .045 \\
Fraction Asian & .130 & .037 \\
Fraction Hispanic & .120 & .532 \\
Fraction White & .720 & .382 \\
Fraction Other & .000 & .002 \\
\hline
\end{tabular}

${ }^{1}$ Comparision here is made using data from ipeds for 2001.

${ }^{2}$ CAP Feeders include UT Arlington, UT San Antonio, UT Tyler, UT El Paso, UT Brownsville, UT-Pan American, and UT Permian Basin.

${ }^{3}$ For CAP Feeder schools, the values of each reported variable have been weighted by 2001 enrollment. 
Table 2: Transfers from CAP Participating Institutions - By Semester

\begin{tabular}{|c|c|c|c|}
\hline Year & Fall Sophomore Year & Spring Sophomore Year & Fall Junior Year \\
\hline 1997 & 11 & 8 & 8 \\
\hline 1998 & 18 & 12 & 13 \\
\hline 1999 & 6 & . & 20 \\
\hline 2000 & 17 & & 20 \\
\hline 2001 & 149 & 6 & 19 \\
\hline 2002 & 278 & 12 & 19 \\
\hline 2003 & 707 & 9 & 21 \\
\hline 2004 & 464 & 15 & 28 \\
\hline 2005 & 417 & 20 & 20 \\
\hline 2006 & 550 & 15 & 20 \\
\hline 2007 & 485 & 11 & 22 \\
\hline
\end{tabular}

${ }^{1}$ Some observations are omitted in order to comply with The Family Educational Rights and Privacy Act 
Table 3: Summary Statistics

\begin{tabular}{lc}
\hline Math Exit Exam & 0.7484 \\
& $(0.5667)$ \\
Reading Exit Exam & 0.5986 \\
& $(0.4661)$ \\
Male & 0.5289 \\
& $(0.4992)$ \\
At Risk of Dropping Out & 0.1018 \\
& $(0.3025)$ \\
Gifted/Talented & 0.2091 \\
Limited English Proficiency & $(0.4067)$ \\
& 0.0024 \\
Economically Disadvantaged & $(0.0489)$ \\
& 0.1032 \\
Asian & $(0.3042)$ \\
African American & 0.2048 \\
& $(0.4036)$ \\
Hispanic & 0.0554 \\
& $(0.2289)$ \\
White & 0.2224 \\
& $(0.4159)$ \\
Other & 0.5142 \\
& $(0.4998)$ \\
Transfers - Texas A\&M University & 0.0029 \\
& 0.0098 \\
Transfers - Texas Tech University & $(0.0988)$ \\
& 0.0058 \\
Transfers - University of Houston & $(0.0763)$ \\
\multirow{2}{*}{$N$} & 0.0208 \\
& 0.1427 \\
& 3,749 \\
\hline S & \\
\hline
\end{tabular}

${ }^{1}$ Standard Deviations are in parentheses.

${ }^{2}$ Summary Statistics for the full sample (within 0.50 grade points of the CAP threshold) are presented here 
Table 4: First Stage

\begin{tabular}{|c|c|c|c|}
\hline & .1 Bandwidth & .25 Bandwidth & .5 Bandwidth \\
\hline Transfer to UT & $\begin{array}{c}0.238^{* * *} \\
(0.0579)\end{array}$ & $\begin{array}{c}0.287^{* * *} \\
(0.0477)\end{array}$ & $\begin{array}{c}0.398^{* * *} \\
(0.0396)\end{array}$ \\
\hline$N$ & 837 & 2,039 & 3,753 \\
\hline R-squared & 0.153 & 0.263 & 0.371 \\
\hline
\end{tabular}

${ }^{1}$ Robust standard errors clustered at hundredths of GPA points are in parentheses.

$* \mathrm{p}<0.1, * * \mathrm{p}<0.05, * * * \mathrm{p}<0.01$

${ }^{2}$ Standard deviations are included in parentheses for the Mean columns

${ }^{3}$ Presented in this table are our coefficients on $\beta_{1}$ from Eq. 1 


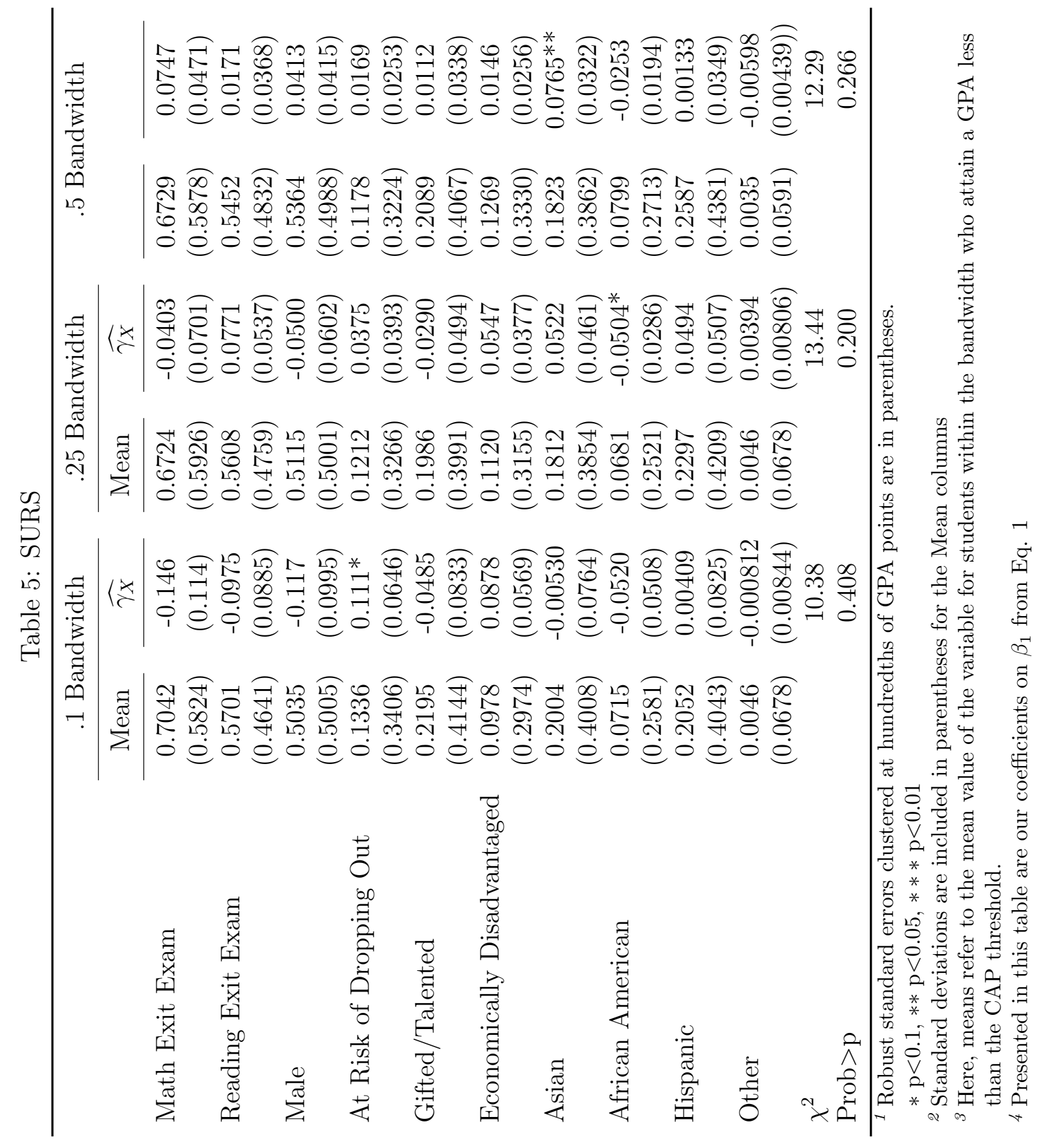




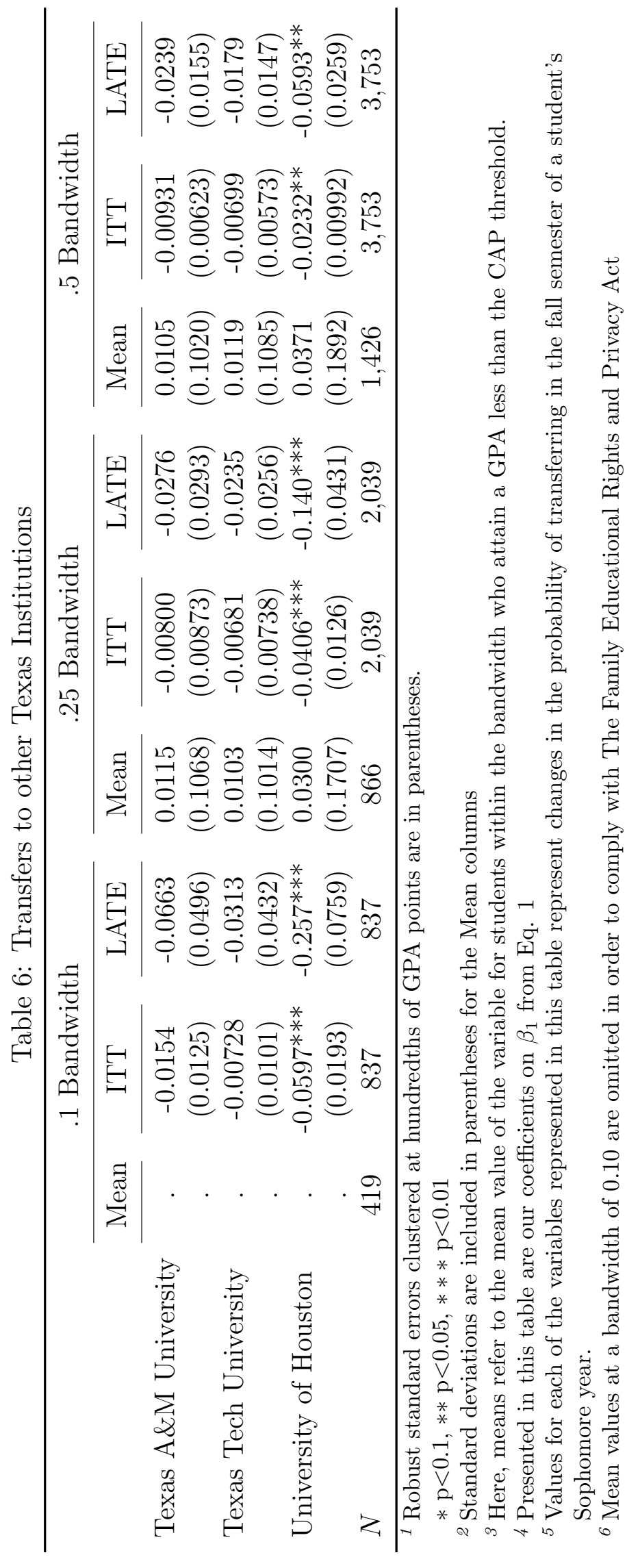




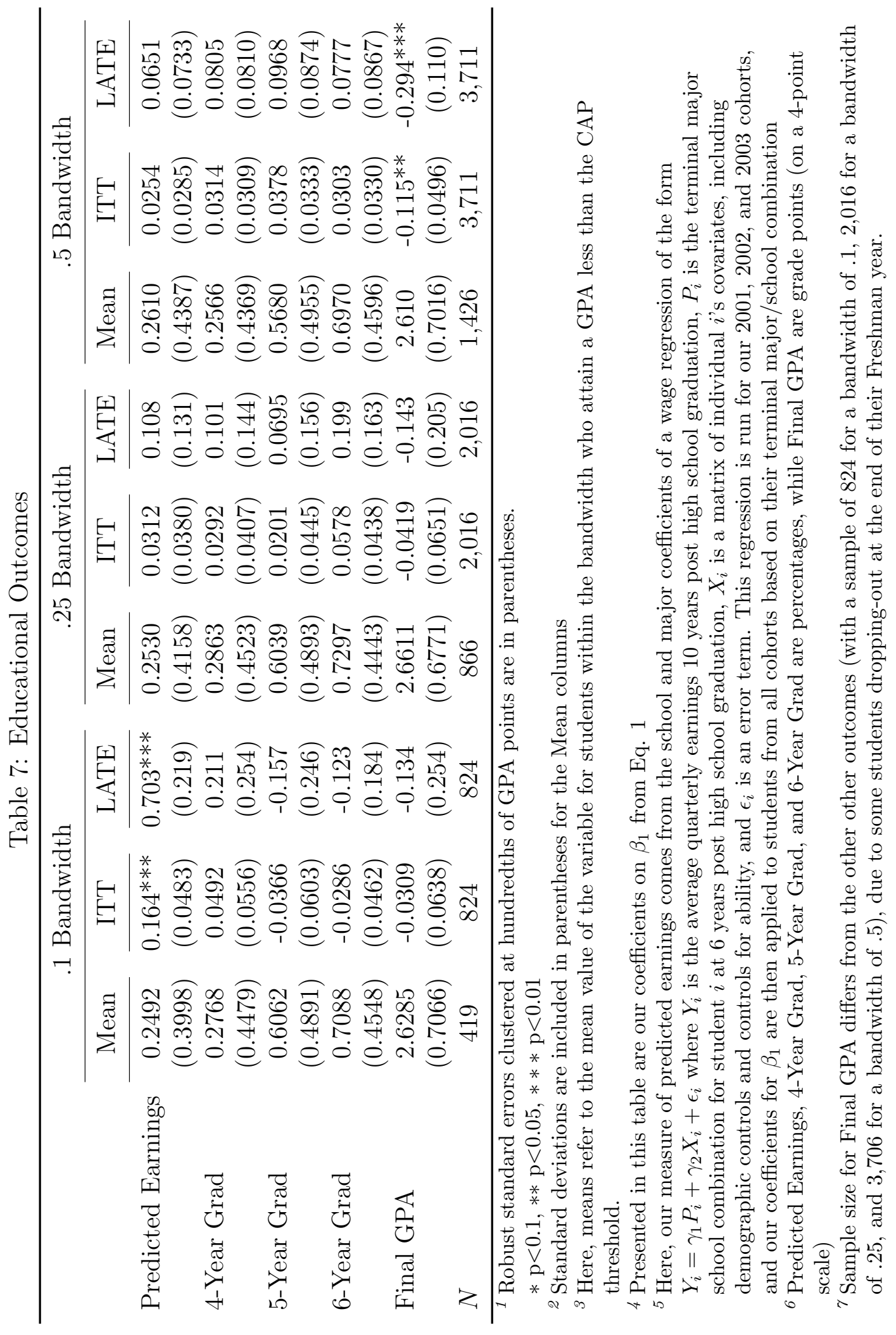




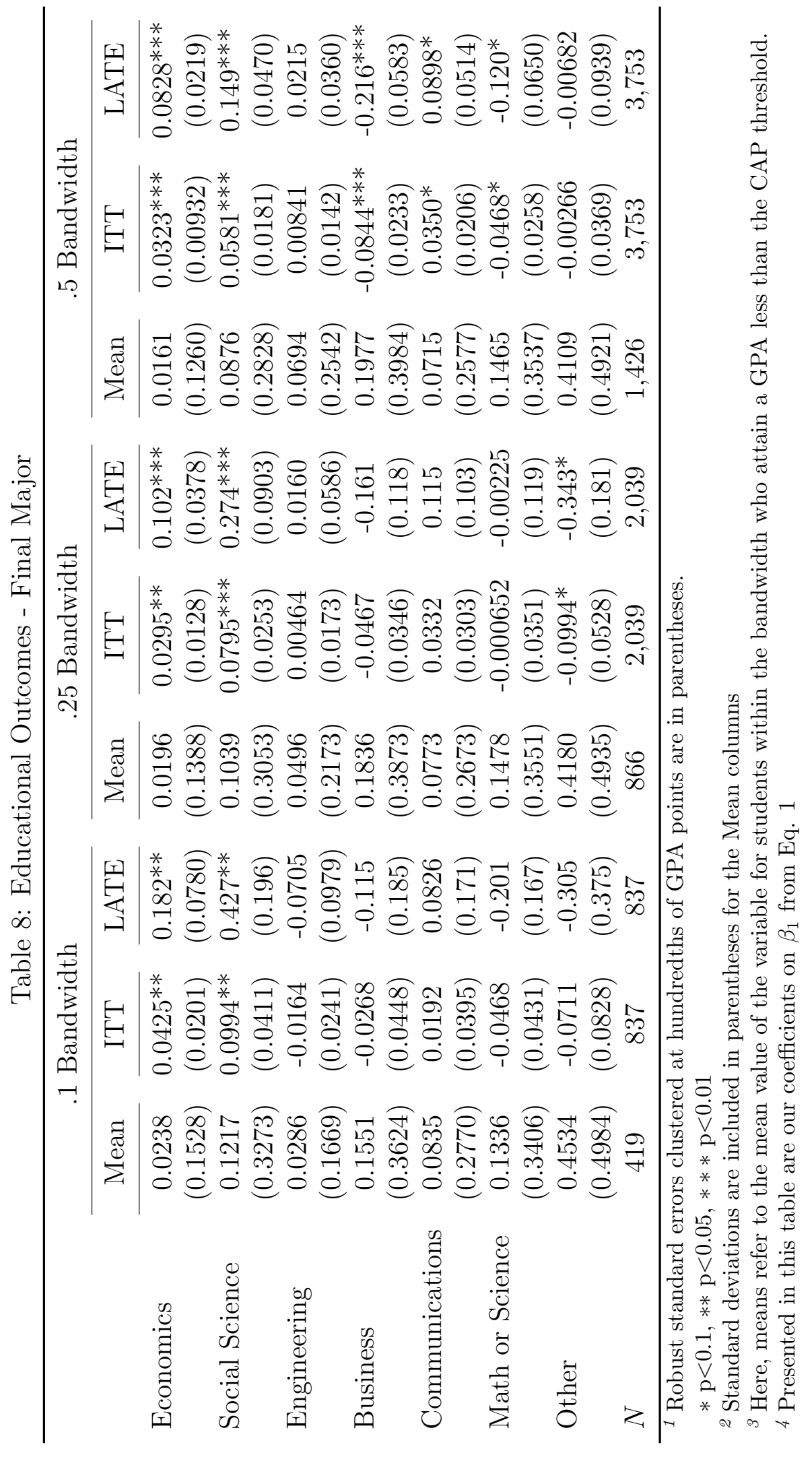




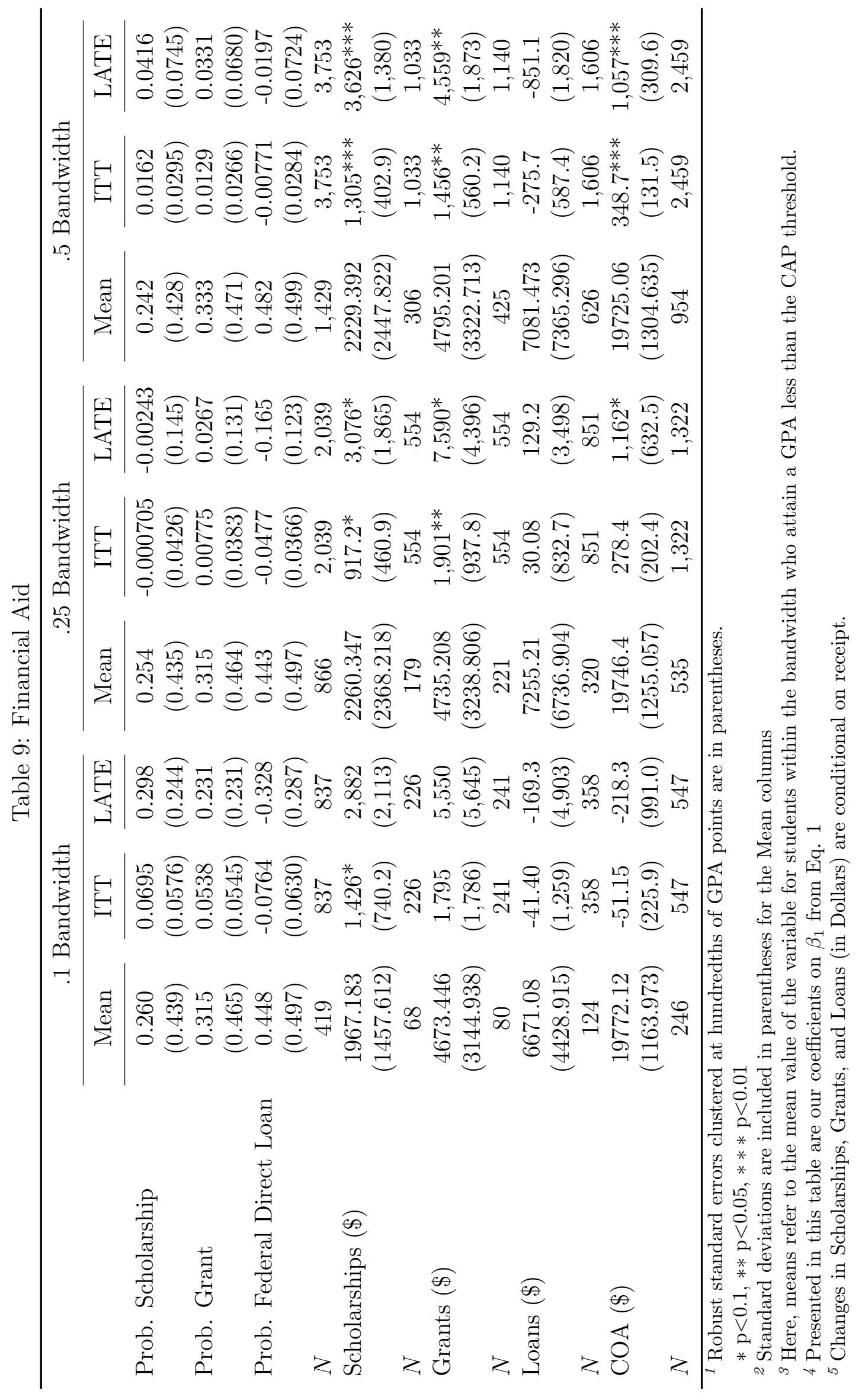




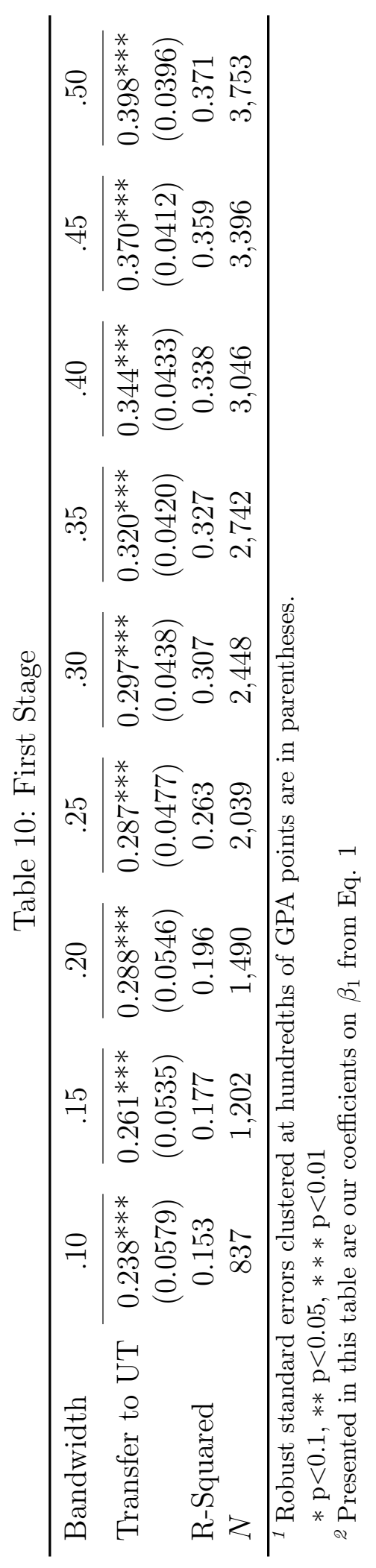




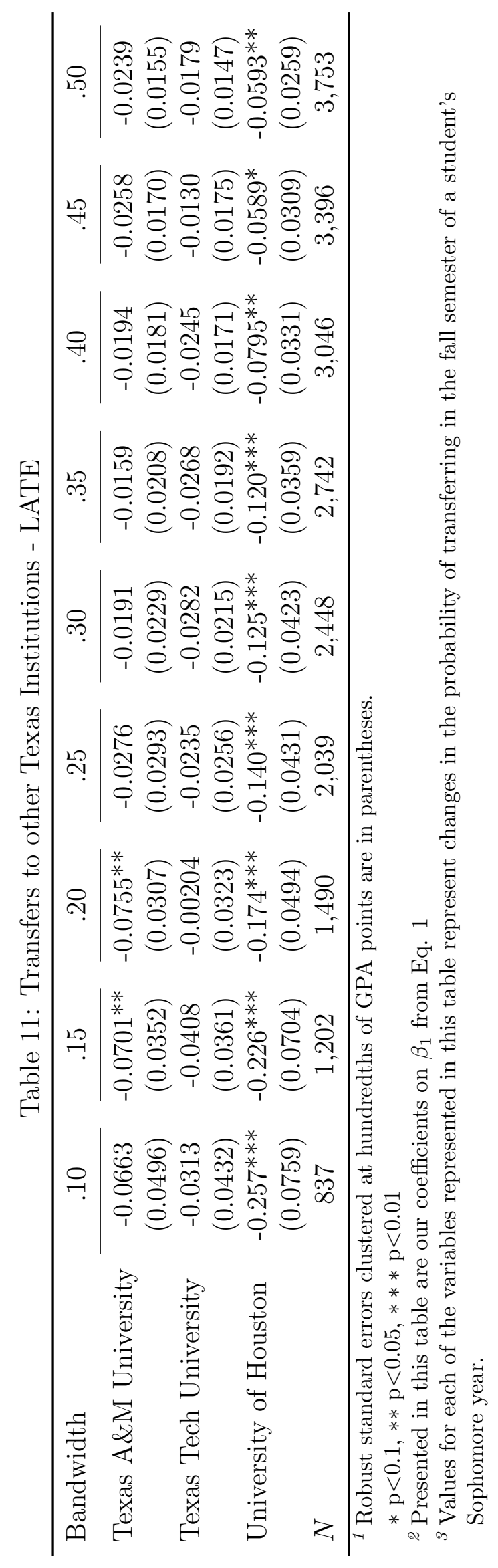




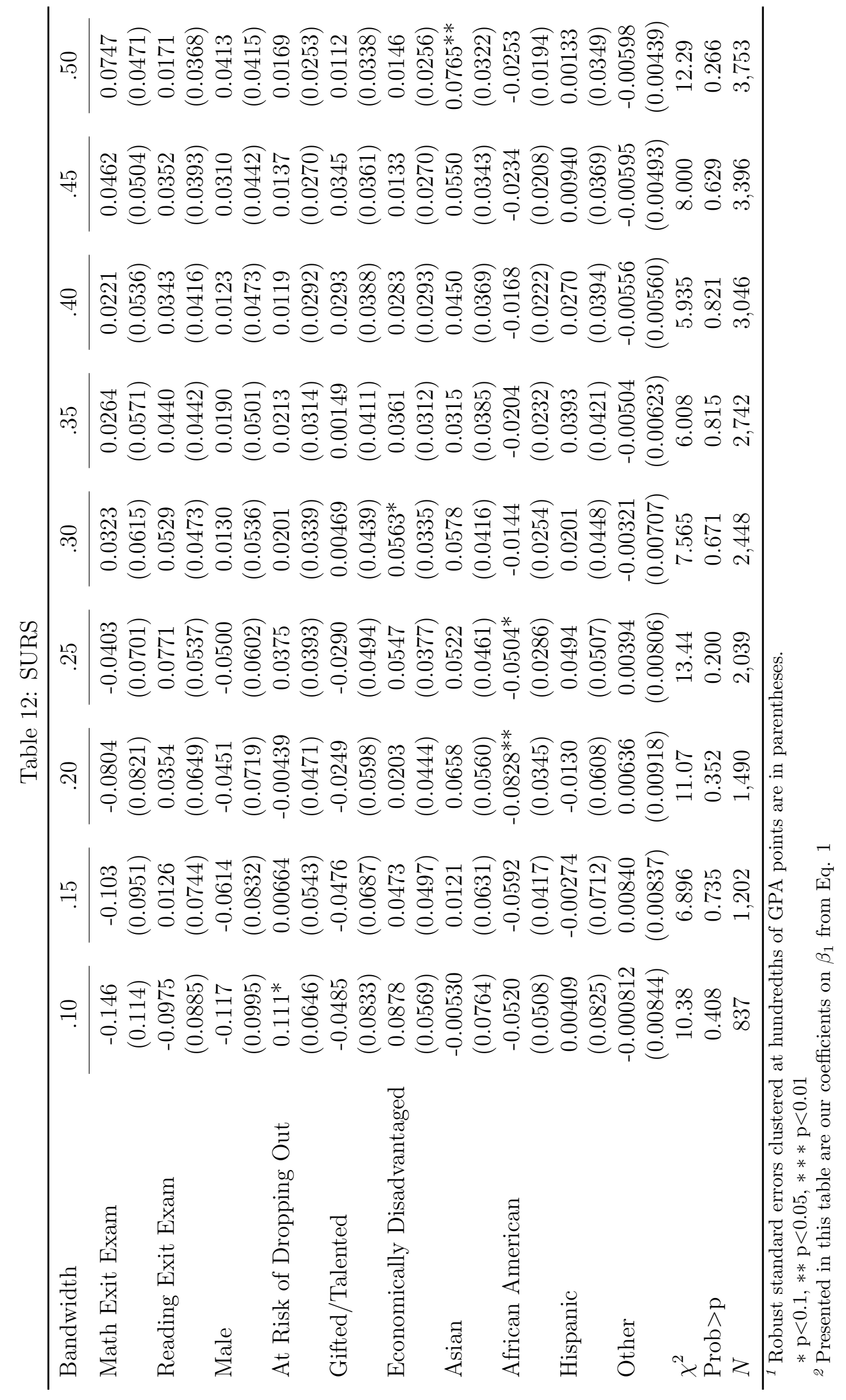




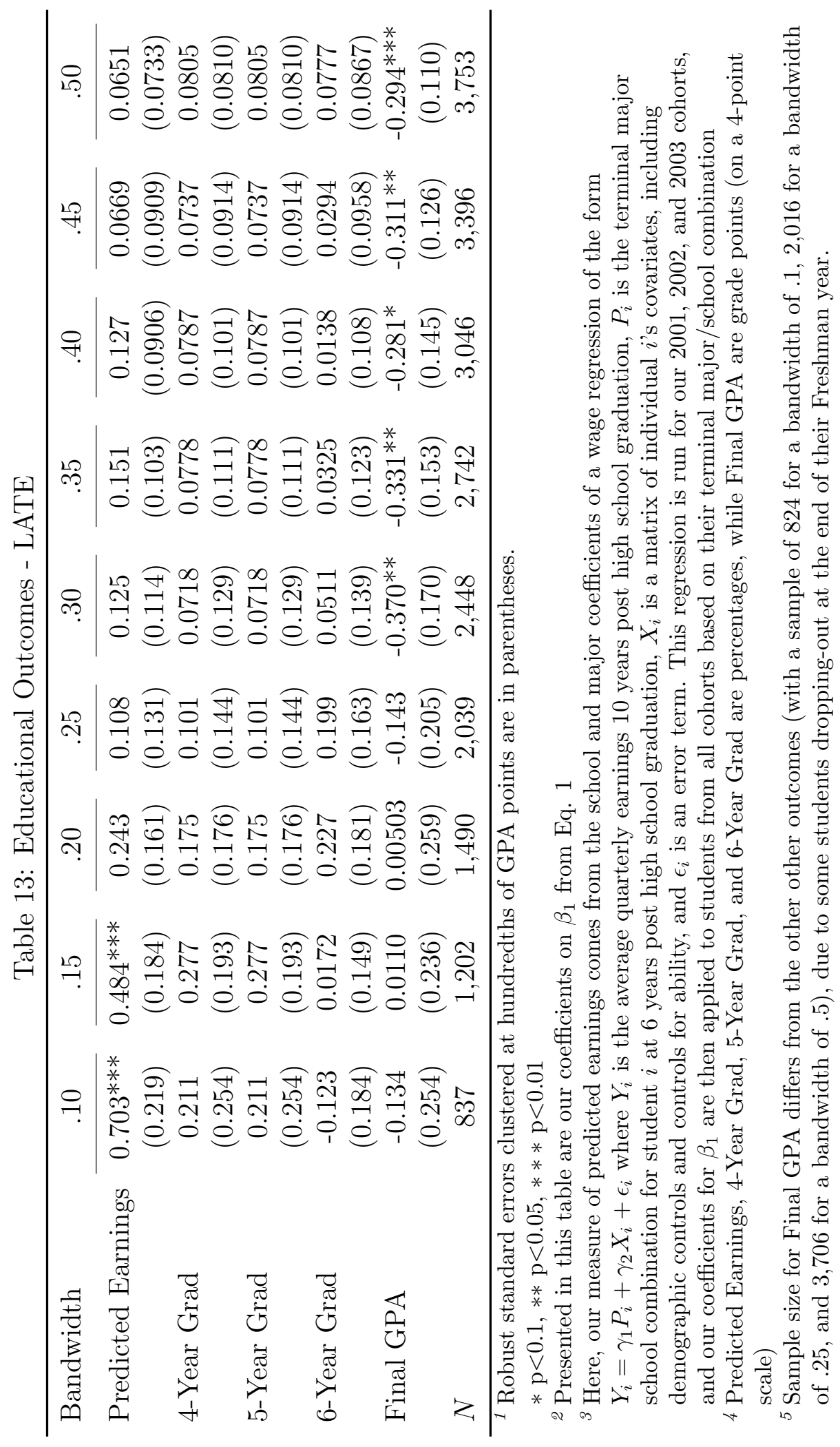




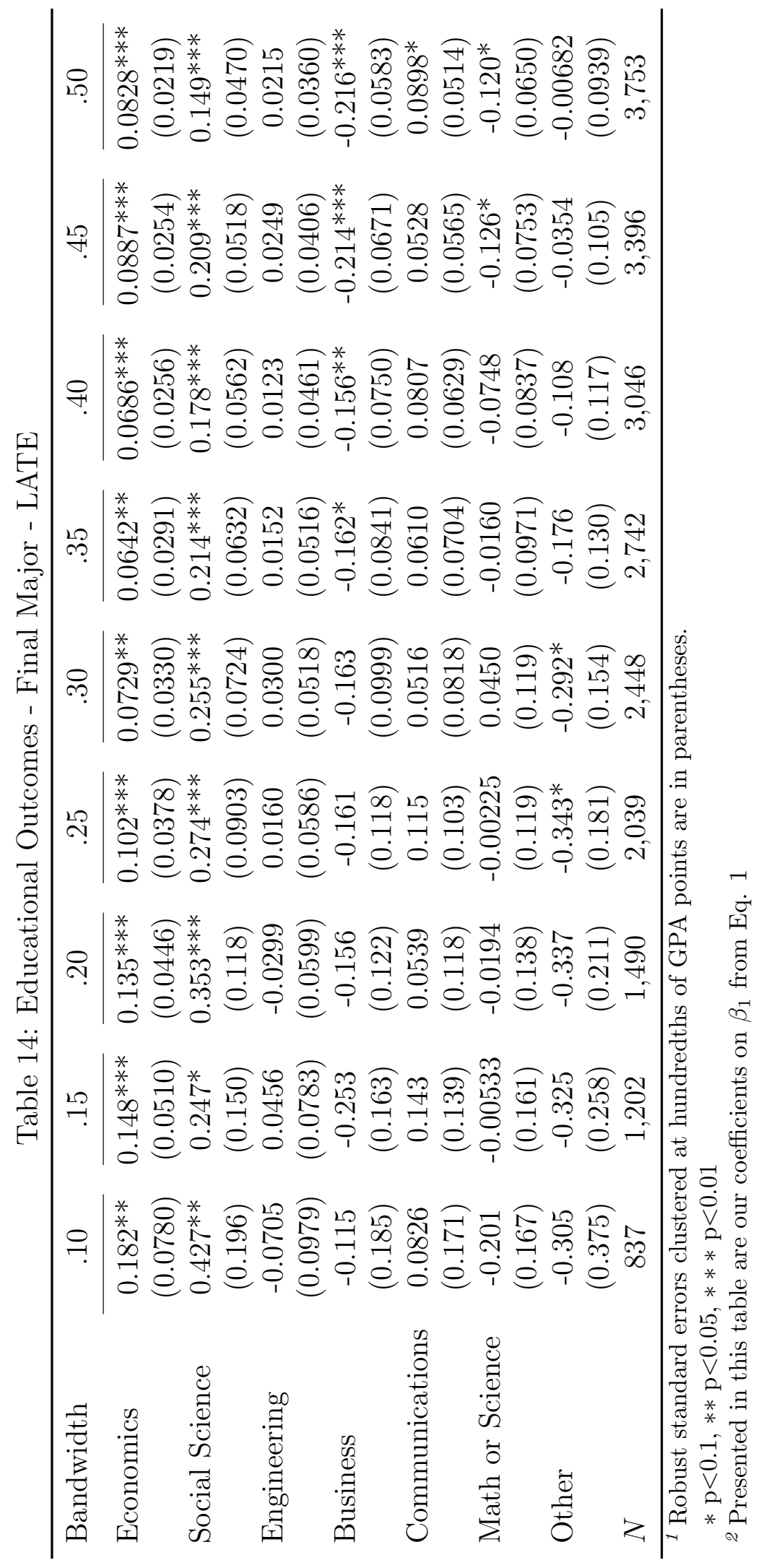




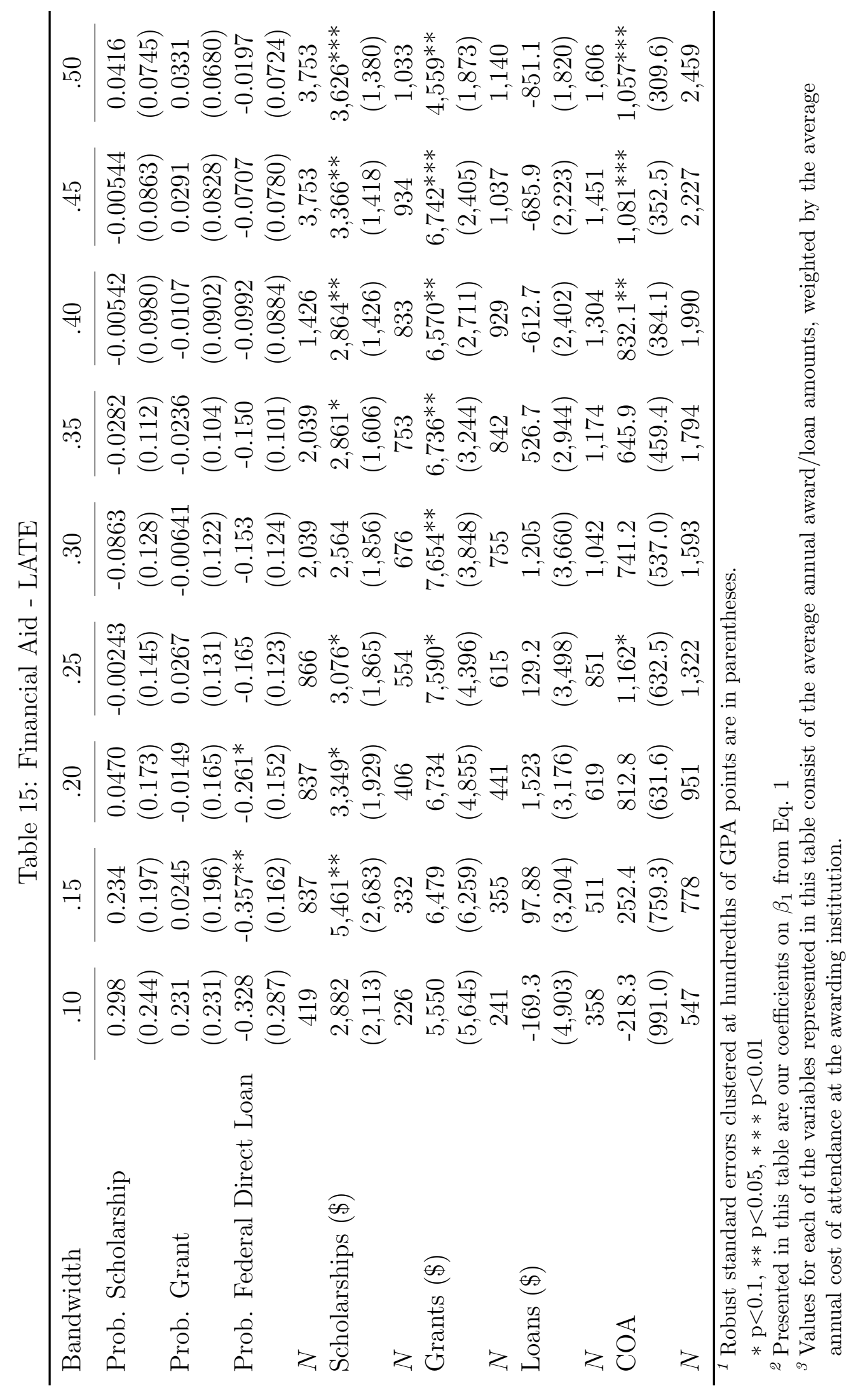

